\title{
الوظائف التنفيذية وعلاقتها باضطرابات التواصل اللفظي لدى ضعاف السمع
}

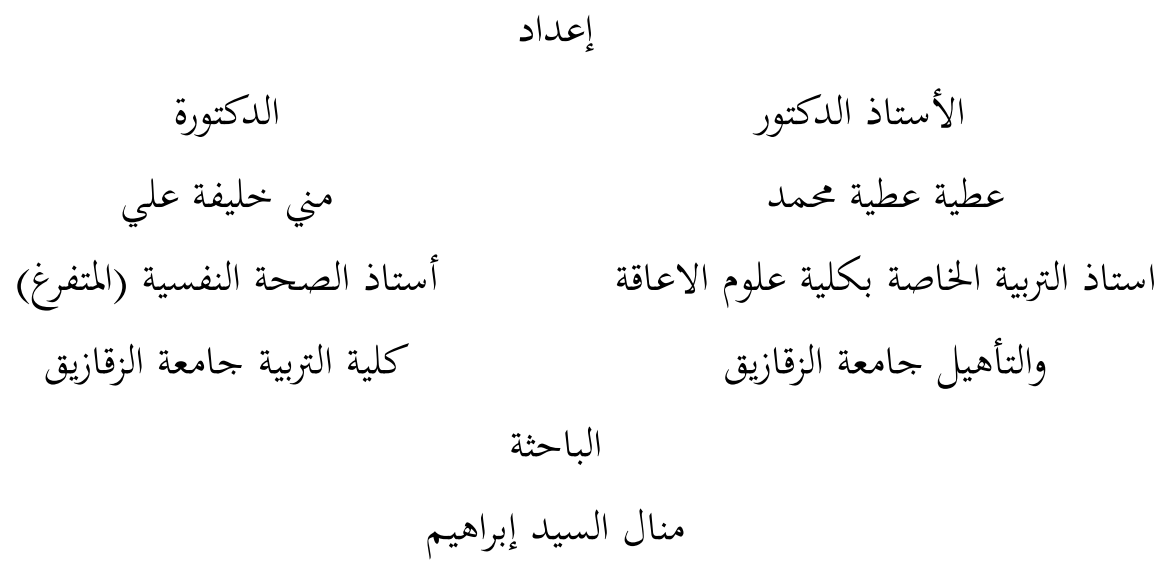




\section{ملخص البحث}

يهدف البحث الراهن إلى دراسة بعض أبعاد الوظائف التنفيذية وعلاقتها وعلاقتها

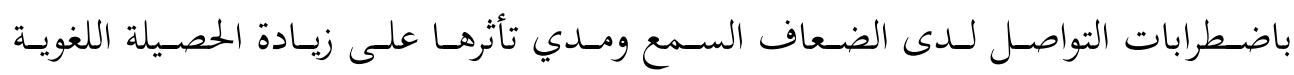

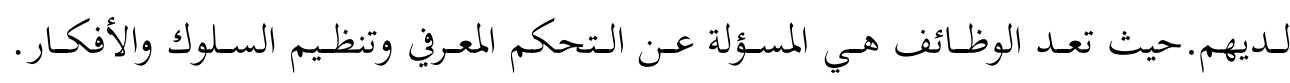

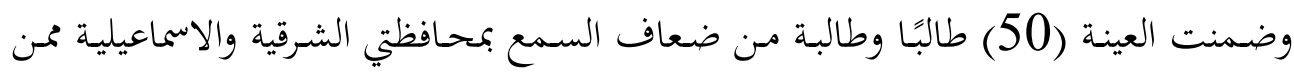
تتراوح أعمارهم بين (9- 12) سنوات, وقامت الباحثة بتطبيق مقياس التواصل اللفظي لضعاف السمع ومقياس الوظائف التنفيذية لضعاف السمع. وتوصل البحث لبن للنتائج الآتية: توجد علاقات ارتباطية موجبة دالة إحصائيًا بين درجات مقياس الوظائف التنفيذية (الأبعاد التياد والدرجة الكلية), ودرجات مقياس التواصل اللفظي (الأبعاد والدرجة الكلية) لدى الأطفال

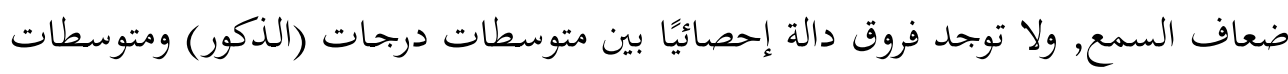
درجـات (الإنـاث) مـن الأطفـال ضـعاف السـمع في مقيساس الوظـائف التنفيذيـة (الأبعـاد

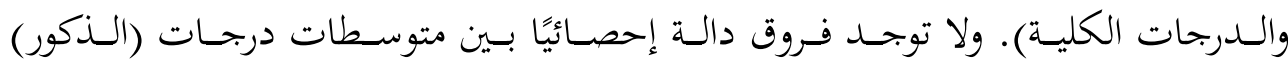
ومتوسطات درجـات (الإنـاث) مـن الأطفـال ضعاف السـمع في مقيـاس التواصل اللفظي (الأبعاد والدرجات الكلية).

الكلمـات المفتاحيـة: الوظائف التنفيذية - اضطرابات التواصل اللفظي - ضعاف 


\section{$\underline{\text { Summary }}$}

The current research aims to study some dimensions of the executive functions, and their relationship to communication disorders among people with hearing impairment and their impact on increasing their linguistic results. Jobs are responsible for cognitive control and regulation of behavior and ideas. The sample included (50) male and female students of hearing impairment in the eastern and Ismaili governorates between the ages of $(9-12)$ years, and the researcher used in the study (1) verbal communication scale for the hearing impaired (prepared) by the researcher). (2) The scale of executive functions for the hearing impaired (prepared by the researcher). The study reached the following results (1) "There are statistically positive correlation relationships between the degrees of the scale of executive functions (dimensions and the total degree), and the degrees of the verbal communication scale (dimensions and the total degree) among children with impaired Hearing, (2) there are no statistically significant differences between the mean scores (males) and the mean scores (females) of children with hearing impairment in the measure of executive functions (dimensions and total grades) (3) there are no statistically significant differences between the mean scores (male) and the mean scores (Females) are children with hearing impairment in the communicative scale $\mathrm{Zi}$ (dimensions college degrees).

Keywords: executive functions - communication disorders hearing impairment 
حاسة السمع تمثل المرتبة الأولى من حيث الأهمية بين الحواس الأخرى، ويدعم ذلك تأكيد قوله سبحانه وتعالي على السمع في عدد كثير من آيات القرآن الكريم، وحتى تلك منك التى يقترن فيها السمع بالبصر بحد أن السمع يتقدم في معظمها.

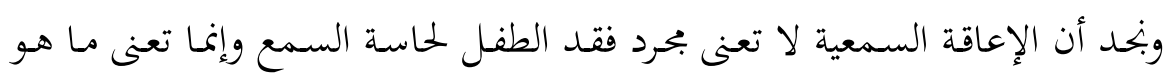
أخطر مـن ذلك، حيت يفقد ما يرتبط بهذه الحاسة من وظائف ومهارات ولعل من أهمها التفاعل مع الآخرين الذين يساعدونه على تعلم اللغة التى تعد من أكثر المهارات أهمية كي يجيا الطفل حياة طبيعية، فهي تؤدي دورًا مهمًا وأساسيًا في تحقيق النمو المناسب للطفل فئ في سئ مختلف الجوانب العقلية، والمعرفية، والاجتماعية، والانفعإلية والدفاعية بل والجسدية أيضا من خلال التعبير الملائم عن حاجته ورغباته ومشاعره (Luetke-Stahlman \& Luckner,

ومن خلال نظرية معالجة المعلومات لتفسير الوظائف التنفيذية تعتمد على تعبير الفرد التلقائي لعملية الضبط، أو تتابع عمليات الضبط كاستجابة مقبولة للتغير في الهدف وذلك في مهمـة معالجـة المعلومـات ويشـمل ذلك ثلاثـة مكونـات لمرونـة الاسـتجابة, هي (تحليـل (Eslinger, 1996, p. المهمة, استراتيجة، أو خطة التحكم والسيطرة, خطة المراقبة).

ومسن خهلال النظريـة السـابقة أعتـبر أن الوظـائف التنفيذيـة مظهرًا مـن مظـاهر التعبير الفـردي, الـذي يختلـف بـاختلاف حـالات الفـــ النفسـية ومتغيراتهـ المختلفــة مـن قـدرات, وعمليات عقلية عليا ومتغيرات شخصية وغيرها (ثناء عبد الودود عبد الحافظ, 2016, ص صريد

\section{مشكلة البحث}

شـعرت الباحثة بالمشـكلة مـن خهلال الدراسـة الميدانيـة للباحثة حيـث تعمل الباحثـة كأخصائية تخاطب, لاحظت الباحثة أن الأطفال ضعاف السمع لديهم قصور في مهارات التواصل باللغة مثل القـدرة على إفـاء وبـدء التفاعلل, والقـدرة على أداء التفـاعلات المركبـة, والقدرة على الاستمرارية في التفاعل. 
كمـا لاحظت الباحثة أن هنـاك مشكلة للدى ضعاف السمع على إنتاج الكـلام

$$
\text { والقدرة على تشفير وتخزين واسترجاع الأشياء المخزنة. }
$$

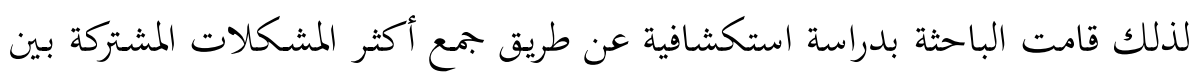

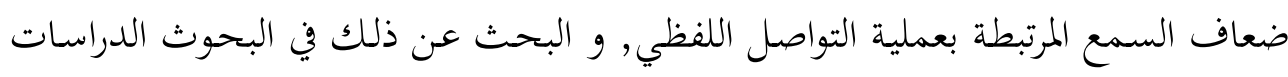

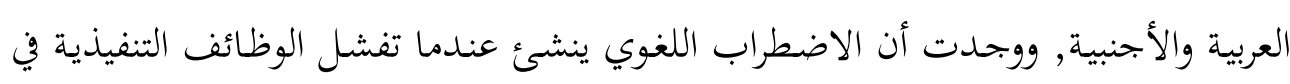

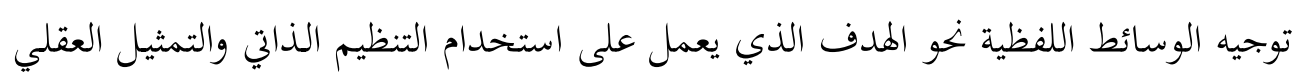
للغة. وبالتالي يضطرب الأداء اللغوي للفرد.

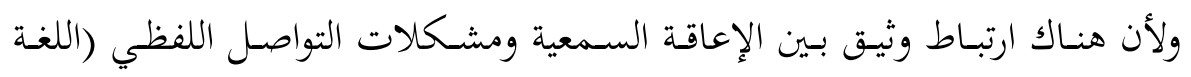

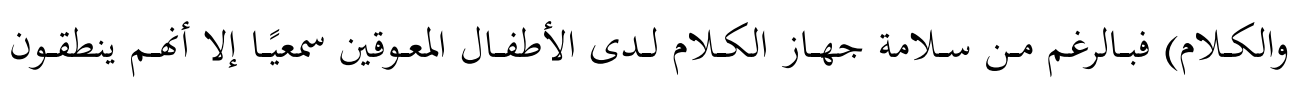

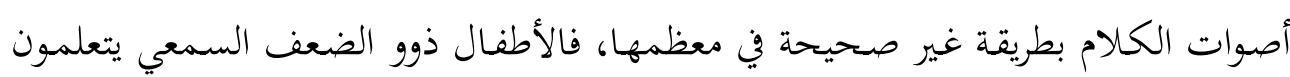

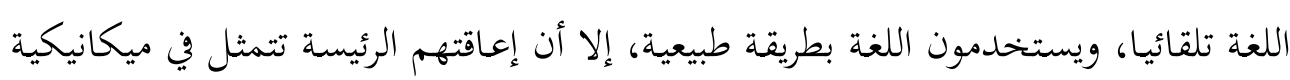

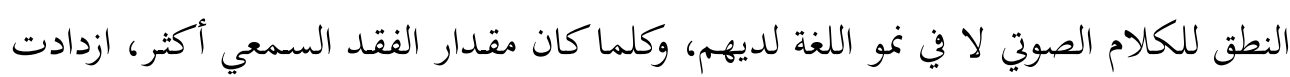

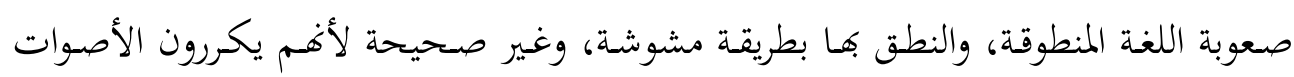

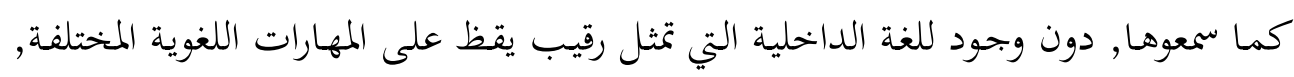

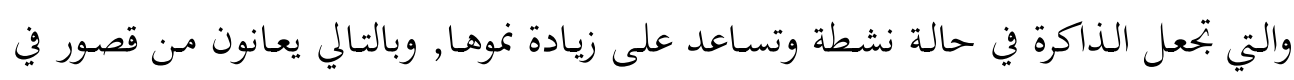
التواصل اللفظي.

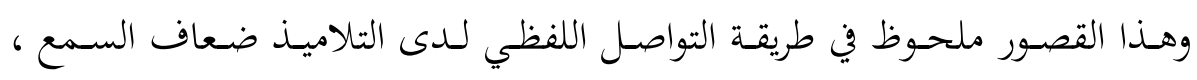

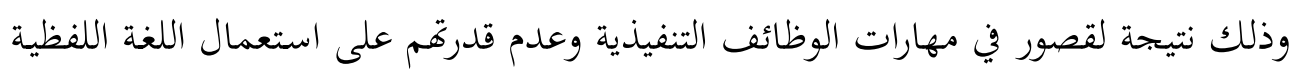

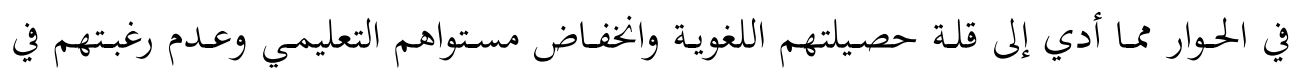

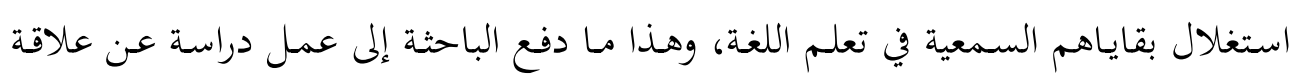
الوظائف التنفيذية مما يؤدي زيادة حصيلتهم اللغوية و تنمية مهارات الحوار اللفظي لديهم.

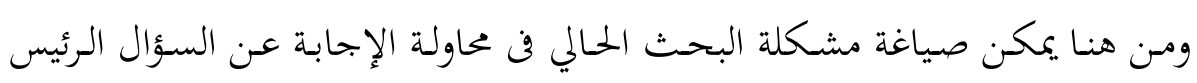

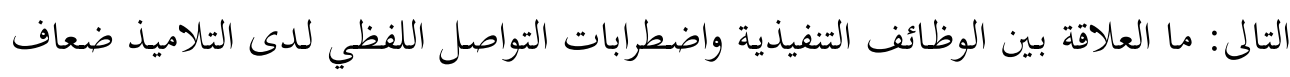
السمع

\section{وينبثق عن هذا السؤال الرئيس عدة أسئلة فرعية وهي:}


هـل توجـد علاقة بين الوظائف التنفيذية والتواصل اللفظي لـدى الأطفال ضعاف

السمع؟

هل توجد بين فروق بين الذكور والإناث من الأطفال ضعاف السمع في الوظائف

التنفيذية؟

هل توجد فروق بين الذكور والإناث من الأطفال ضعاف السمع في التواصل اللفظي؟

$$
\text { أهداف البحث }
$$

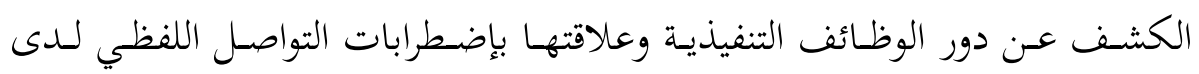

$$
\text { الأطفال ضعاف السمع }
$$

التقليل من المشكلات اللغوية التى يواجهها التلاميذ ضعاف السمع

\section{أهمية البحث}

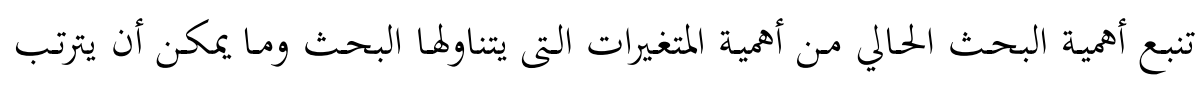

$$
\text { عليها مستقبل التلاميذ ضعاف السمع ويمكن توضيح هذه الأهمية في الآتى: }
$$

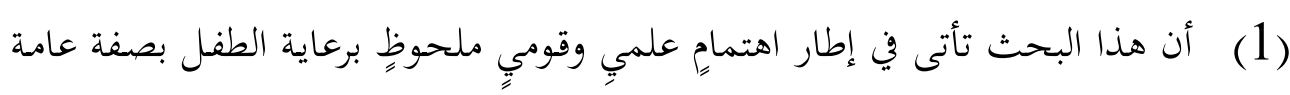
وللطفل المعاق بصفة خاصة وبضعاف السمع على وجه التحديد. (2) العمل على تنشيط الوظائف التنفيذية المسئولة عن تخزين الألفاظ والتعبير اللفظي. (3) حاجة الأطفال ضعاف السمع في المرحلة الابتدائية لتنمية الحصيلة اللغوية لديهم.

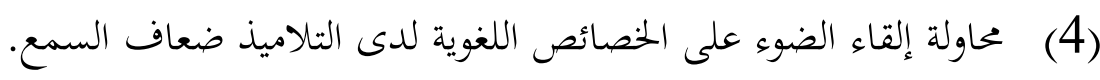

\section{مفاهيم البحث الإجرائية}

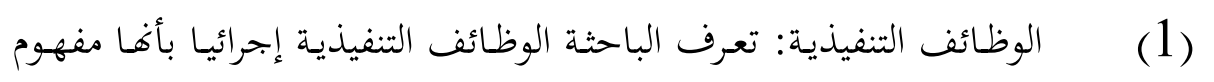

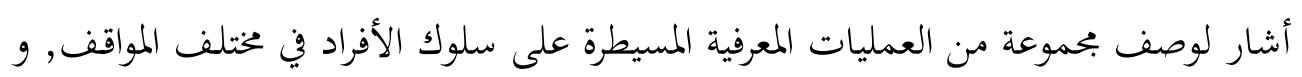
يشمل (التخطيط - الذاكرة العاملة - المراقبة الذاتية - المرونة العقلية - التحكم الانفعالي) 
وتقاس بالدرجة التي يكصل عليها أفراد العينة على مقياس الوظائف التنفيذية المستخدم في

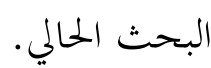

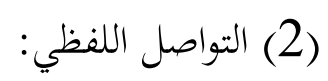

تعرف الباحثة التواصل اللفظي اجرائيا بأنه اللغة المنطوقة التي يتم من خلالها التواصل

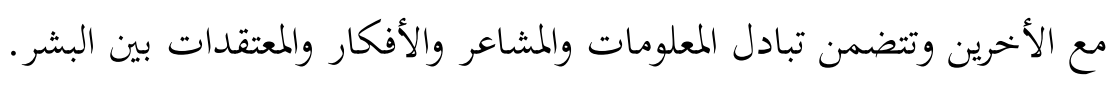

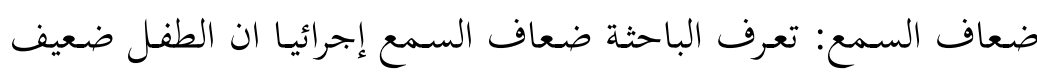

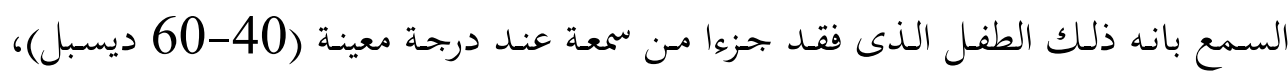

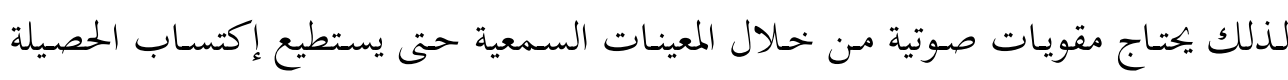
اللغوية والمشاركة مع الآخرين والتواصل معهم.

$$
\text { الإطار النظري: }
$$

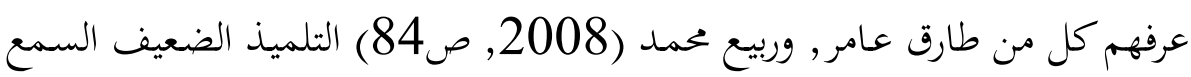

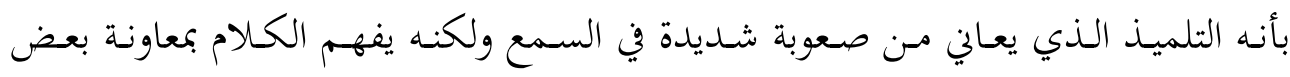

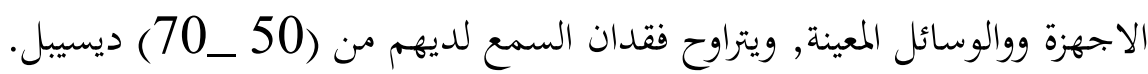

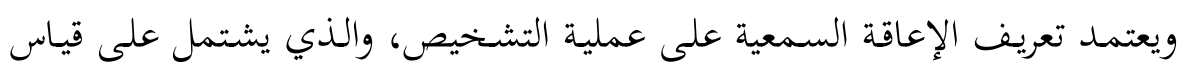

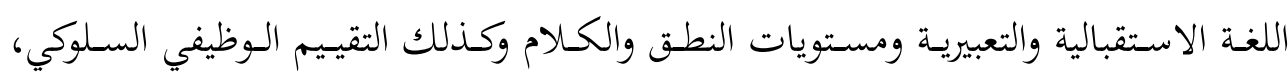

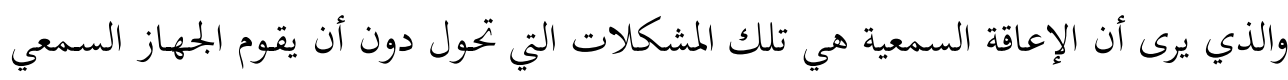

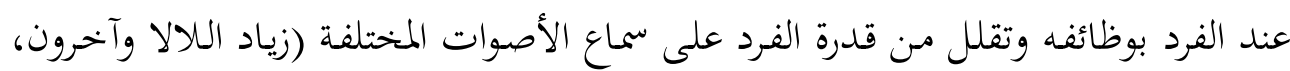

$$
\text { 2015، ص 200). }
$$

\section{Functional Definition المنظور الوظيفي للإعاقة السمعية}

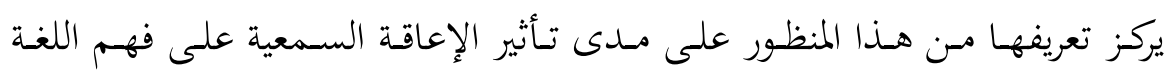

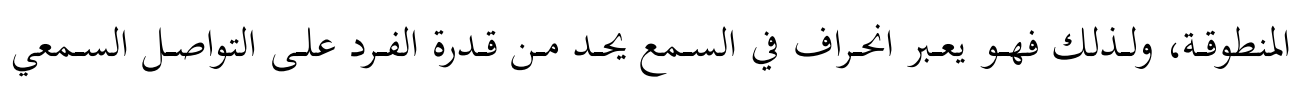

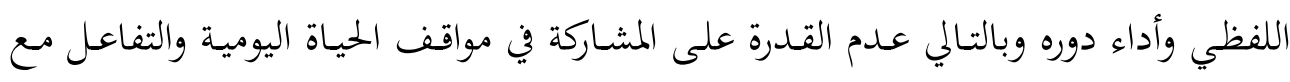
الآخرين (Stach, B., 2010,p. 220). 
مما سبق بحد ان التعريفات تتفق على (ان الطفل ضعيف السمع بانه ذلك الطفل

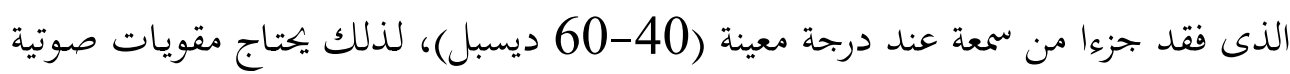

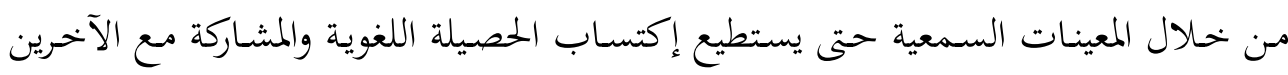
والتواصل معظم.

\section{ثانيًا: التواصل اللفظي}

أشار كل من Adler, \& Rodman, (2006 p.4) إلى التواصل اللفظي أنه عملية استجابة بشرية لسلوك رمزي من الآخرين، وقدما ثلاثة خصائص تميز التواصل اللفظي وهي خصوصيته بالإنسان دون غيره من الكائنات فهو الكائن الوحيد الذي يتواصل فئل لفظيًّا،

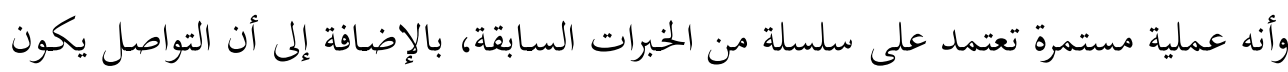

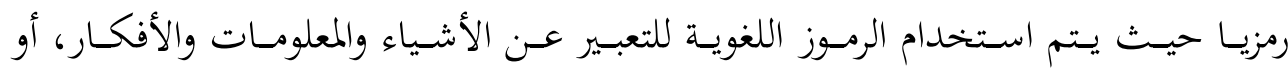

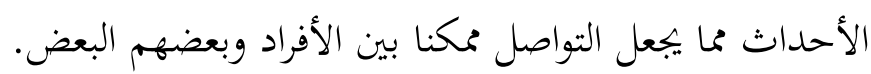

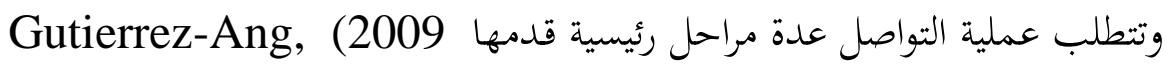
(p.6)

1 ) المتكلم: هو الشخص الذي يقوم بنقل الرسالة سواء لفظيًا، أو غير لفظيًا. 2) الرسالة: هي المتوى الذي يتم تنظيمه وتشفيره باستخدام اللغة التي يفهمها المرسل. 3) القناة: هي الوسيط الذي يستخدمه المرسل في تشفير وفك شفرة الرسالة. 4) المستقبل: هو الشخص الذي يقوم بفك رموز الرسالة التي قدمها له المرسل. 5) التغذية الراجعة: هي استجابة المستقبل للرسالة التي قدمها له المرسل.

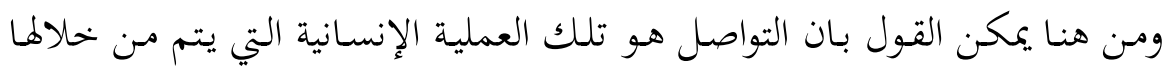

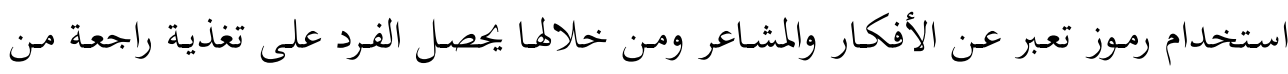

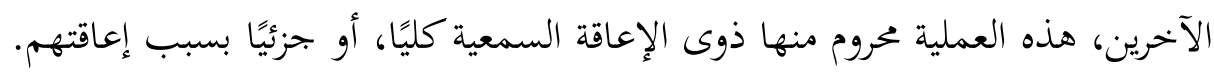
وأضاف Stewart, \& Clarke, (2003, p.25) مهارة أخرى للغة اللفظية هي مكون محصول اللغة: ويقصد به معرفة الطفل بالمفردات اللغوية.

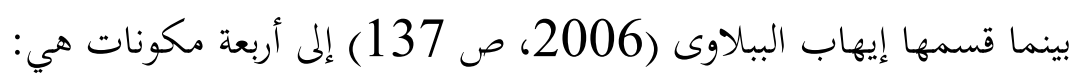


1) المستوى الفونولوجي: وهو الذي يبحث في النظم والأنماط الصوتية والنظام الصوتي

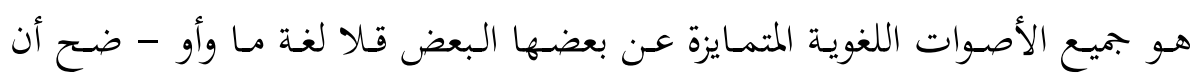

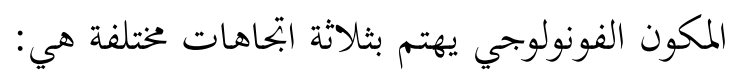
أ- الخصائص المادية وتشمل اختيار الأصوات وتنظيمها.

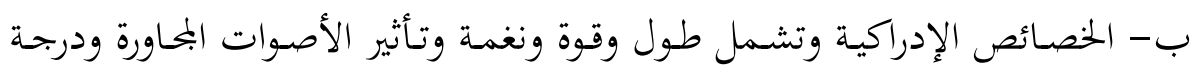
ارتفاع الصوت وتردده. - مان.

ج- الخصائص الإنتاجية وتشمل مدة الصوت ومكانة وطريقة النطق ودور الأجزاء الصوتية.

2) المسـتوى المورفولـوجي: ويهتم بدراسـة تراكيـب الكلمـة ويصف كيـف تتكـون

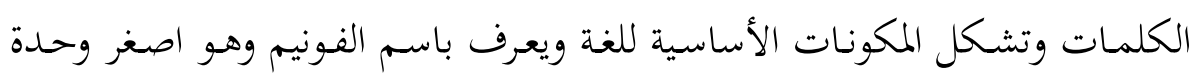

$$
\text { ذات معنى. }
$$

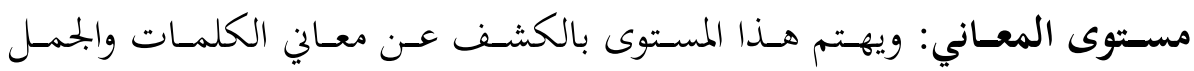

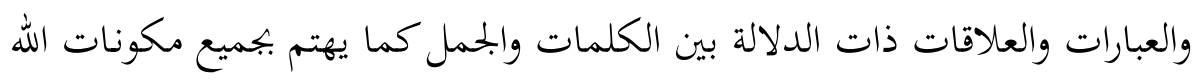

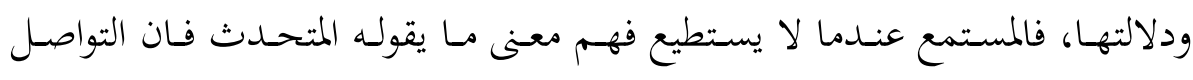
ينقطع بينهما. المستوى البرجماتي: ويقصد به دراسة القواعد التي تحكم استخدام اللغة في المواقف

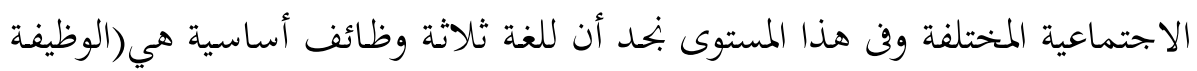
الأدائية، الوظيفة التنظيمية، الوظيفة التفاعلية)

\section{نظريات تفسر التواصل:}

أشار زيدان عبد الباقي (1974) أن هذه النظريات بدأت في شكل صور بدائية لا

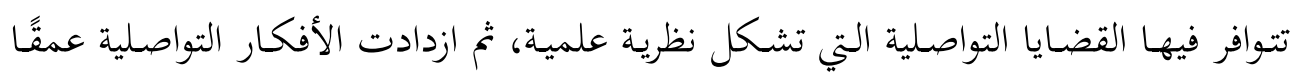

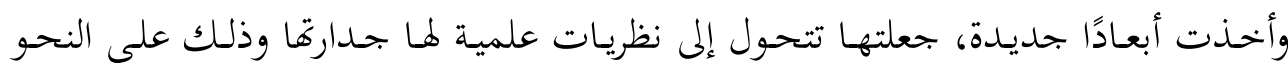


إن الطفل البشرى منذ لحظة ميلاده يتميز بالخصوبة التواصلية التي تمتاز بها الطبيعة

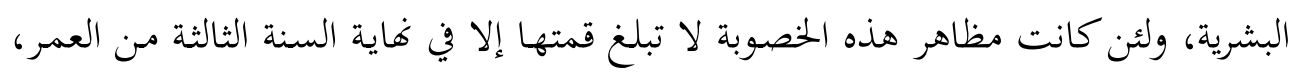

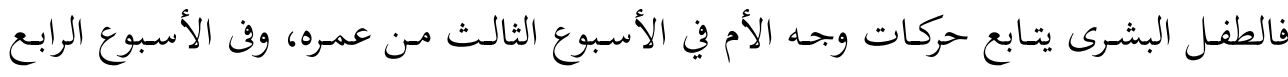

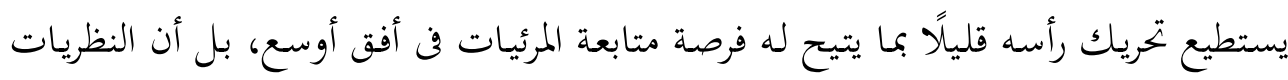

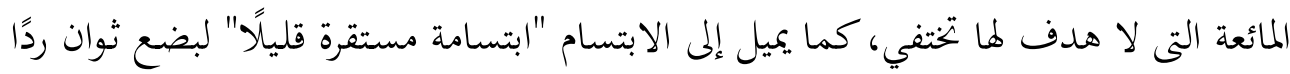

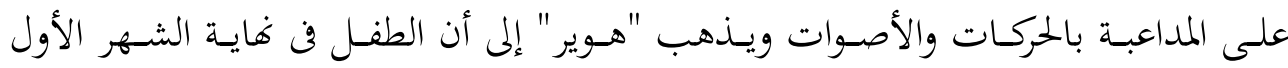

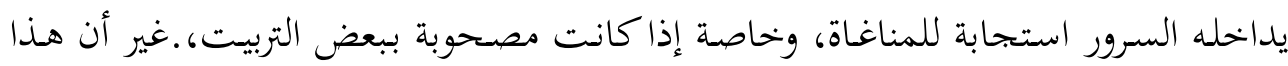

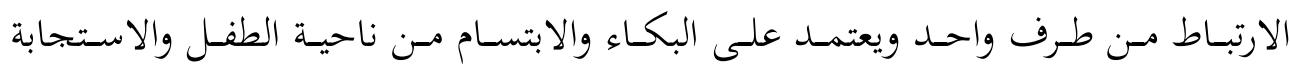

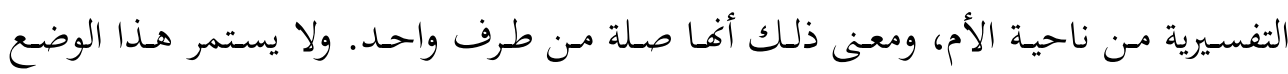

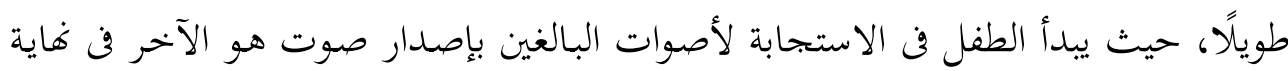
الأسبوع السابع من عمره. لاحظ "شتيرن" حدوث ذلك في فاية الأسبوع التاسع. ومن هنا تبرز أهمية الصوت

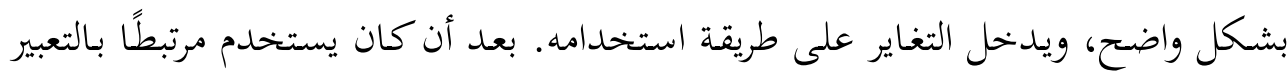

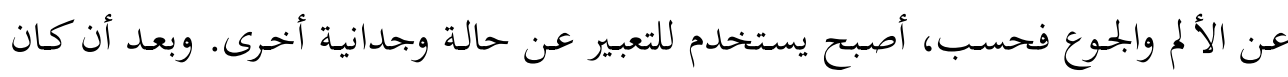

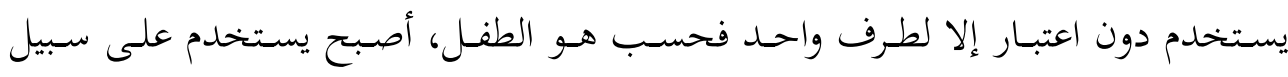

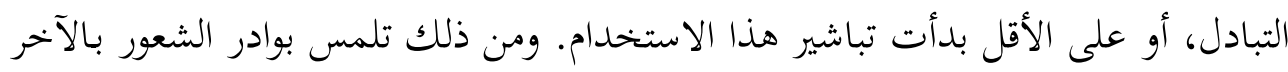

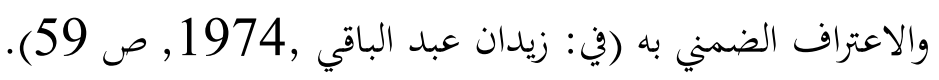

\section{نظرية "ويفر وشانون" فى التواصل:}

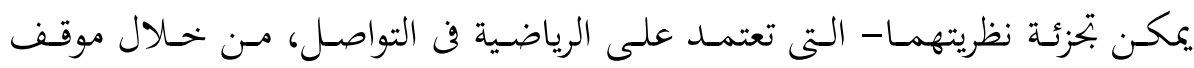

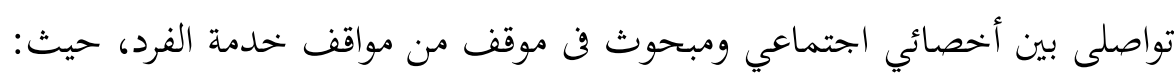

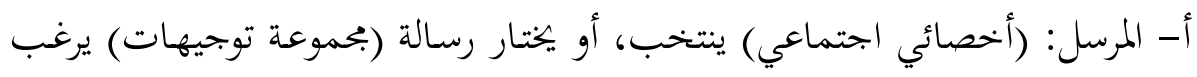

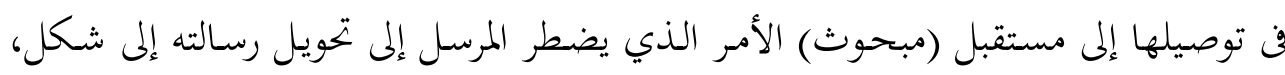

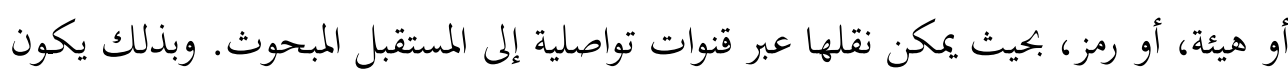

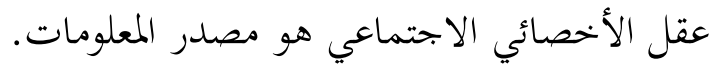




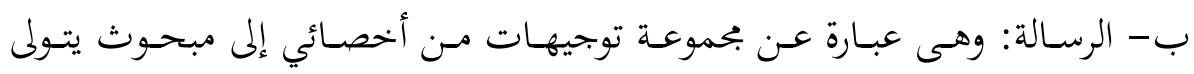

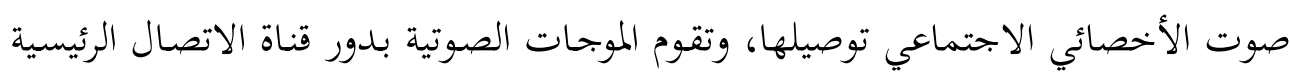

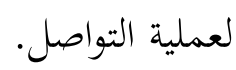

ج- المستقبل: وهو الذي يتلقى الرسالة ويقوم بتحويلها إلى الشكل، أو الرمز الذي

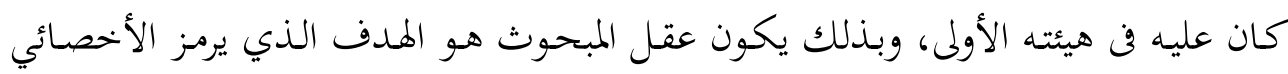

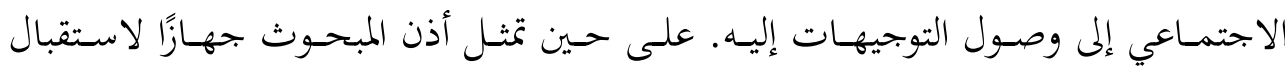
المعلومات (في: زيدان عبد الباقي , 1974, 61).

\section{نظرية "لازارسفليد" في التواصل:}

تعتمد نظريته على دراساته الميدانية في فياس استحابات المستمعين للإذاعة كوسيلة

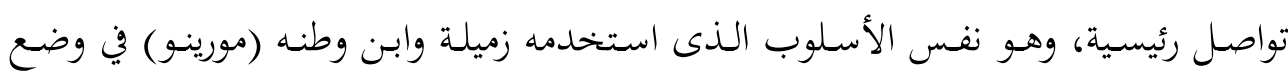

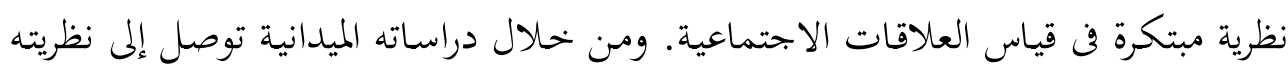

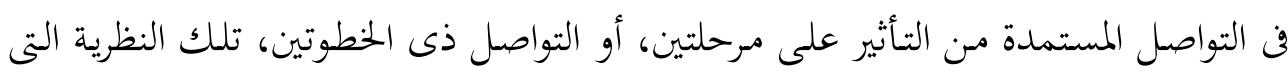

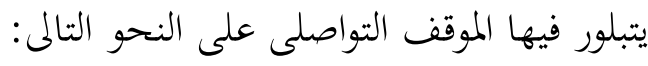
أ- المرسل: وهو الذى يؤلف وينقل الرسالة.

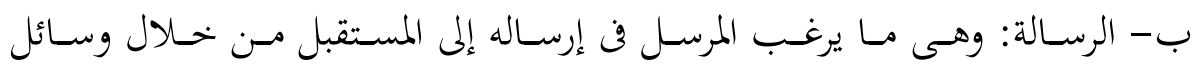

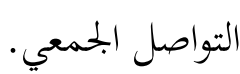

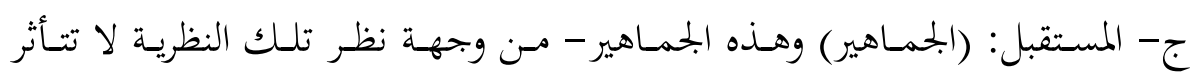

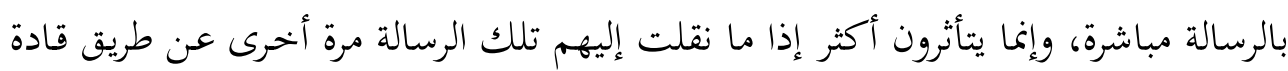

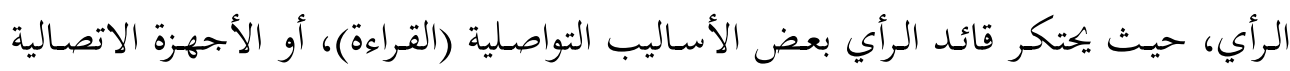

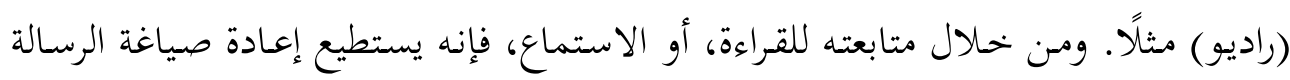

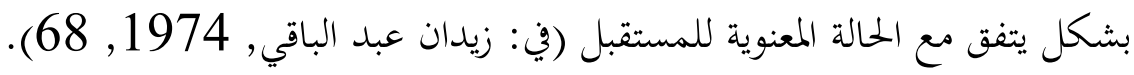


أشار إليها محمد عبد الحي (1994) حيث تعتبر نظريه كولن Colin من النظريات

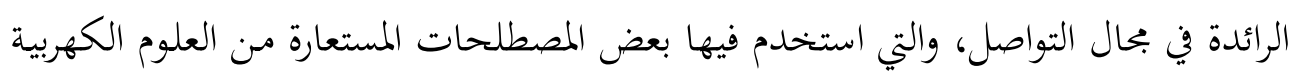
والإلكترونية: 1- مرسل، 2- الرسالة، 3- التدفق، 4- المستقبل، 5- 5- التغذية الراجعة.

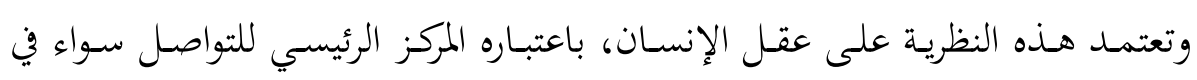

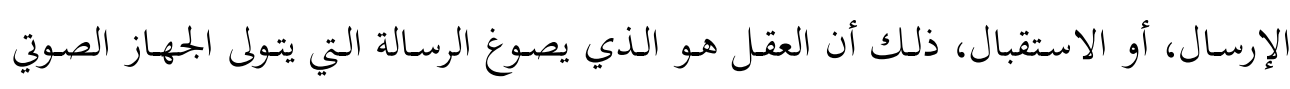

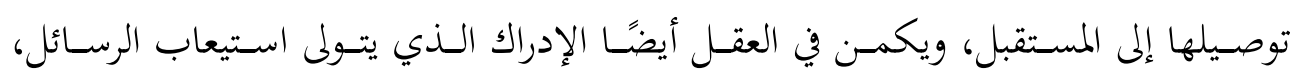

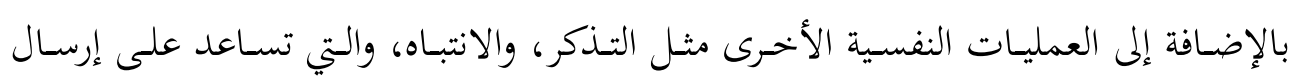

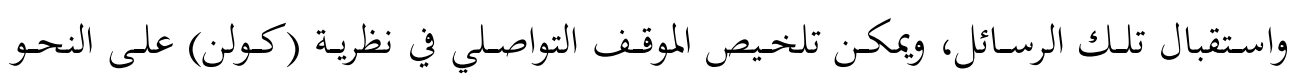

أ- المرسل: الذي يستخدم من عقلة الرسالة التي يرغب في توصيلها إلى شخص آخر. ب- الرسالة: التي يصوغها بعقلة في شكل يمكن إدراكها من المرسل إليه.

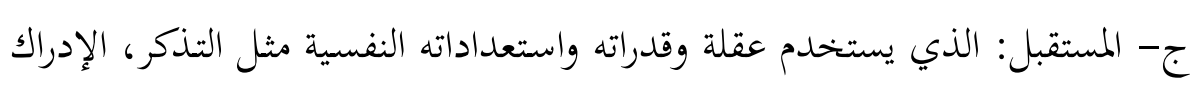
والانتباه، في استيعاب تلك الرسالة.

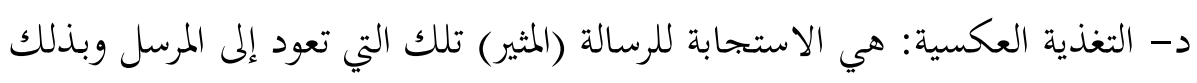

تكتمل الدورة التواصلية.

من الملاحظ أن تلك النظرية تعتمد على الدراسات النفسية، وتعتبر من النظريات المتكاملة لقيامها على أساس أن التواصل دورة مستمرة.

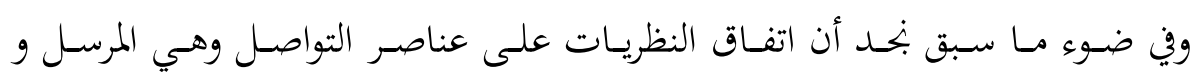

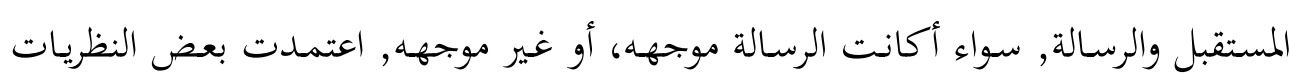

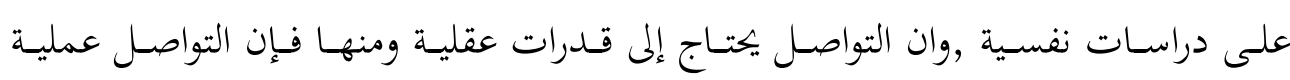

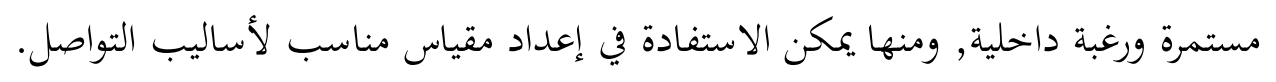

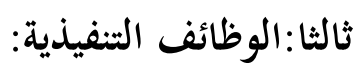

تعـرف الوظـائف التنفيذيـة بأهـا القـدرات المعرفيـة التي تـنظم وتتحكمم في كـل مـن

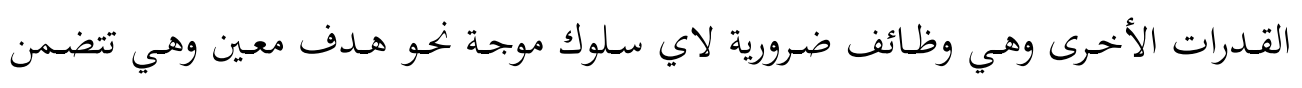


التخطيط والتحويل والمراقبة الذاتية والتعميم والذاكرة العاملة والكف والمرونة (السيد سعد،

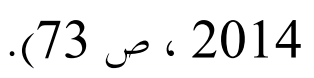

ويري علماء النفس أمثال (landry, (2003, p.6 أن الوطائف التنفيذية تبرز

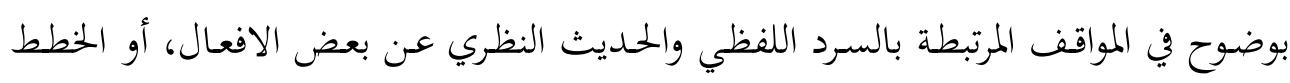

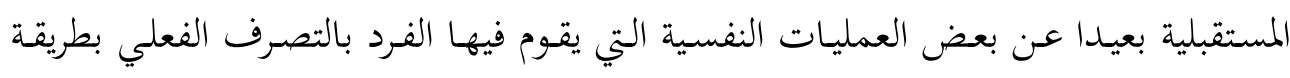

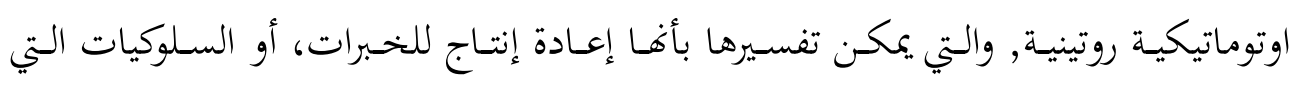

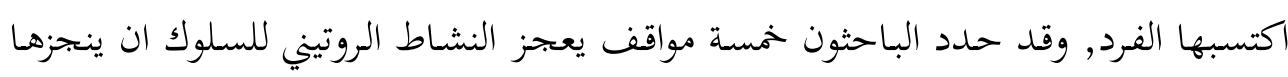

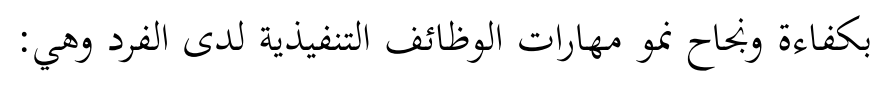

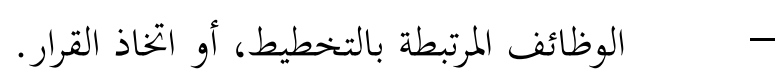

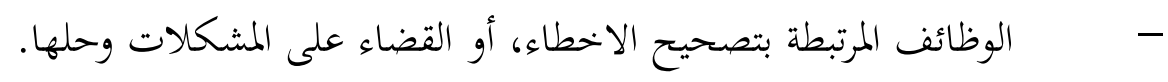
- - المواقف التي يكون فيها الفرد لم يتعلم بعض الاستجابات المطلوبة بطريقة

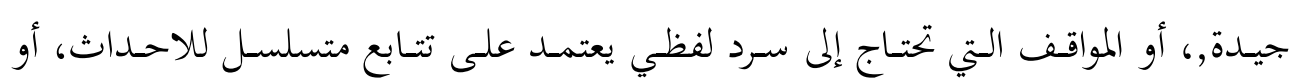
التصرفات - - - ماتمواقف الخطيرة، أو المواقف المرتبطة بفنيات وتقنيات صعبة. - - ملمواقف التي تتطلب التغلب على استجابات لعادات قوية ومتأصلة فنيا، أو المواقف التي تتطلب مقاومة المغريات القوية من خلال التنظيم الذاتي.

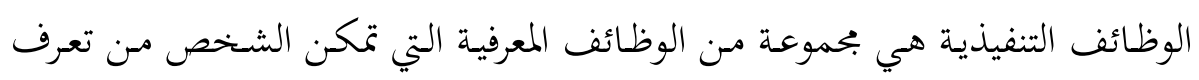

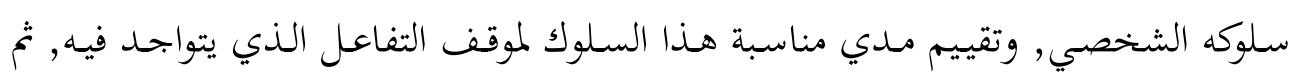

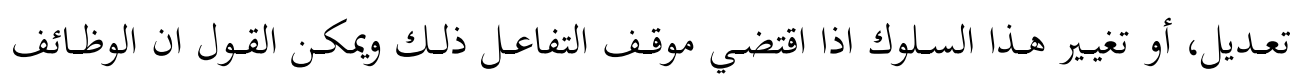

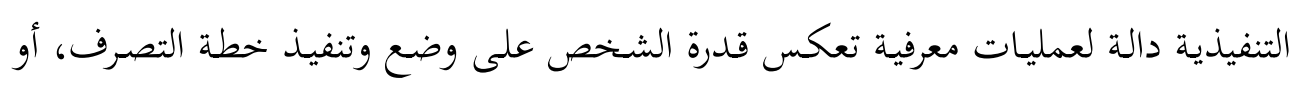

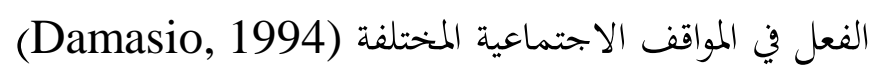
ونتعرف على الوظائف التنفيذية من خهلال بعض المهارات الأساسية وهي السيطرة

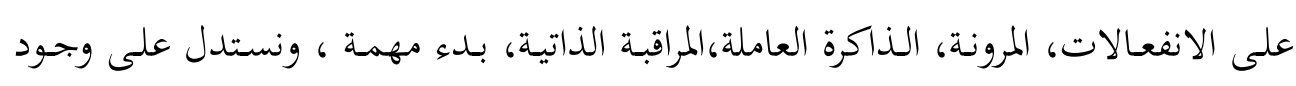

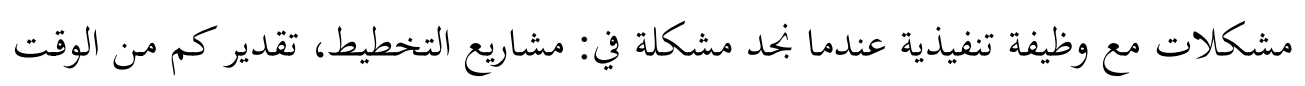


سيستغرق المشروع لاستكمال سرد القصص( لفظيا، أو كتابيا)، الحفظ بلدء الأنشطة، أو المهام، التذكر Morin (2014 (20).

ممـا سبق بنحد ان اتفقت التعرفات على ان الوظائف التنفيذية مهارات عقليـة عليـا

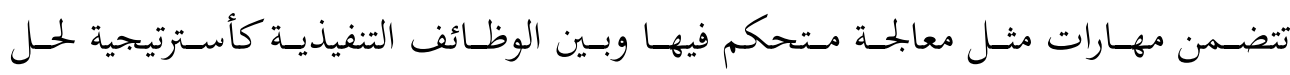

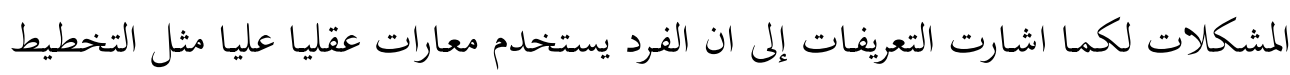

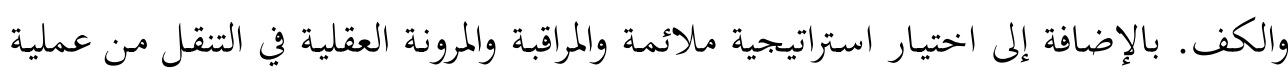
لاخري في ضوء هدف, ساعيًا لحل المشكلة.

\section{نماذج الوظائف التنفيذية نxecutive Functions Of Exels}

\section{نظرية لوريا Luria s Theory}

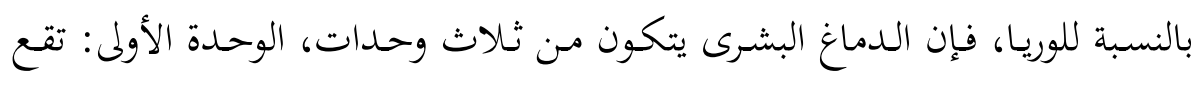

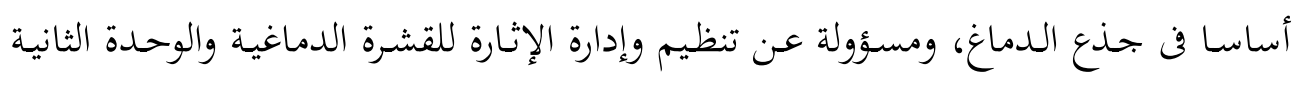

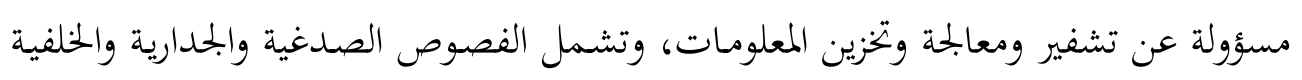

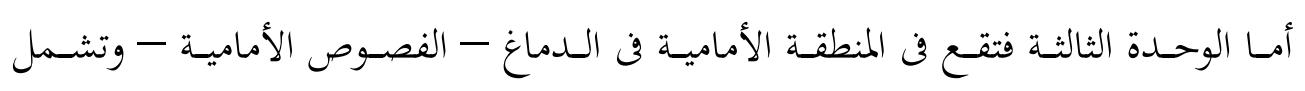
وظائفها بربحة وتنظيم وتنفيذ وتحقق السلوك الإنسانى (Luria, 1973).

supervisory Attentional System Model

$$
\text { نموذج جهاز الإشراف الانتباهى }
$$

النموذج الذى أعده نورمان وشاليس، فإن بربحة وتنظيم وتوضيح الأفعال الإنسانية

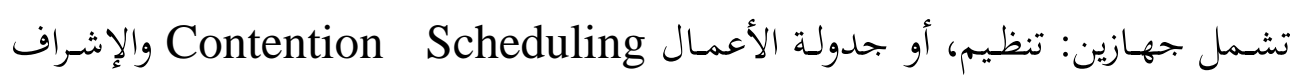
الانتباهى Supervisory Attentional والجهاز الأول مسؤل عن السلوكات الروتينية

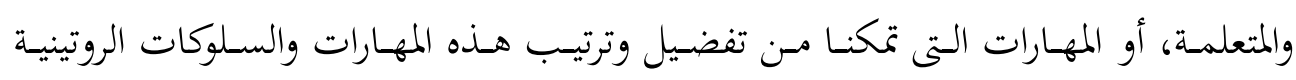

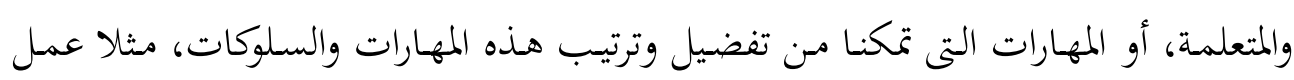

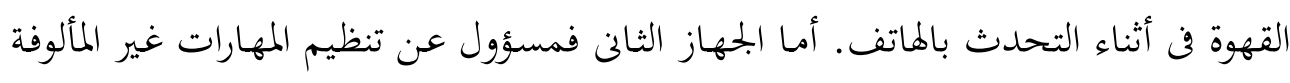

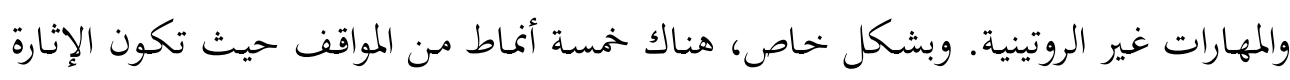


التلقائية والروتينية للسلوك غير كافية للأداء الفعال والمثالى. وهذه المواقف تشمل التخطيط

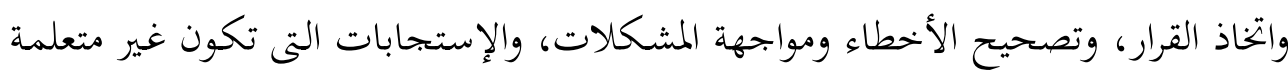

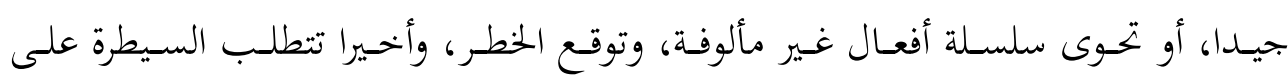

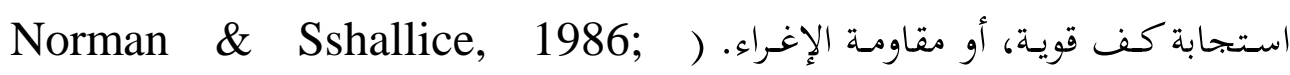
.(Alexander; Shallice; Picton; Binna \& Macdonal, 2005

نموذج ستس وبنسون (Stuss and Benson Model)

اقترح هذا النموذج ثلاثة أجهزة يتفاعل بعضها مع بعض، وذلك لضن لضبط انتباه الفرد ووظائفه التنفيذية وهى جهاز الإثارة الشـبكى الأمـامى ( Anterior reticular (activating system

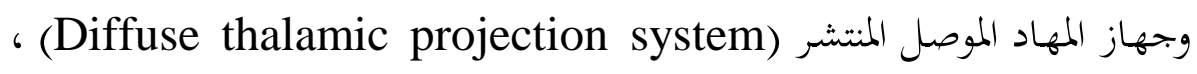

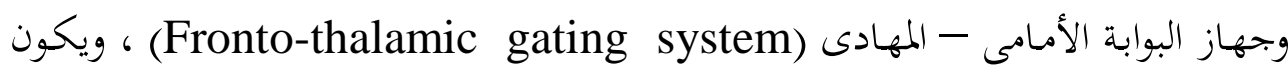
الجهازان الأوليان مسؤولين عن إدامة يقظة الفرد، أما الجهاز الثالث فمسؤول عن ضبان الثبط

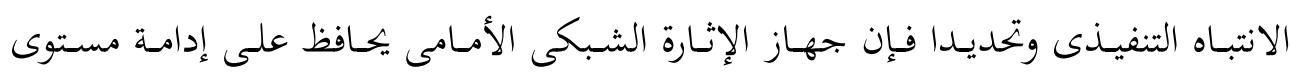

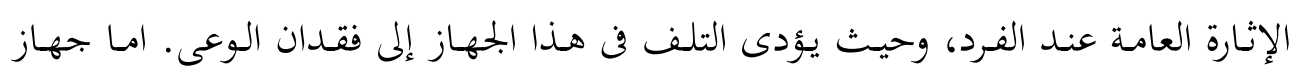

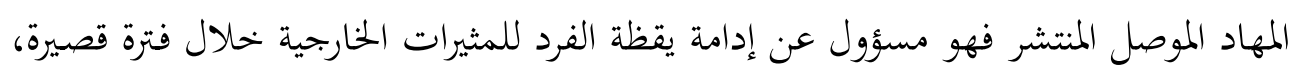
ويؤدى التلف فن هذا الجهاز إلى التشتت بوساطة المثيرات الخارجية.

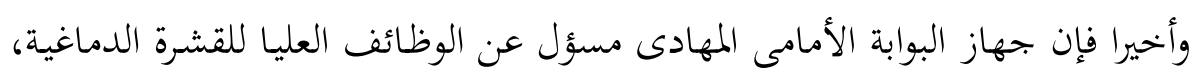

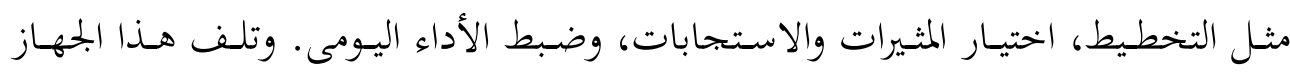

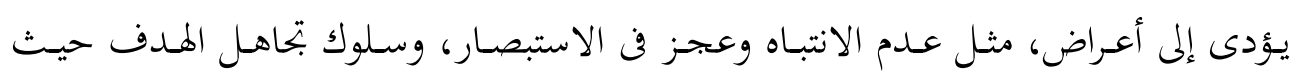

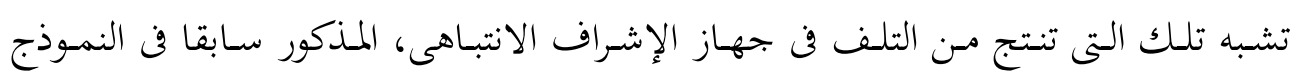

وقد طور ستس وآخرون العلاقة بين نظام، أو جهاز الإشراف الانتباهى والنموذج

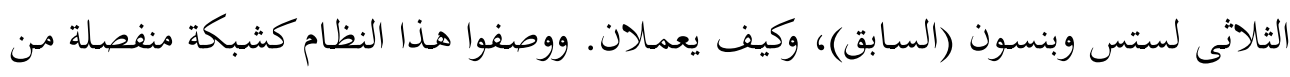

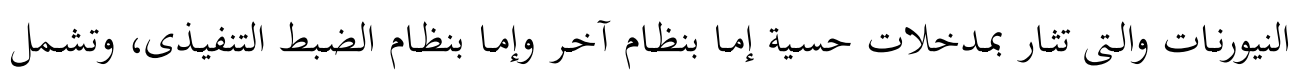


الانتباه والمسؤول عنه (frontal right) ، والتركيز والمسؤول عنه (cingulate area) والمشاركة والمسؤول عنها (cingulate and orbitofrontal areas) ، والكف والمسؤول عنه Dorsolateral

Dorsolateral والتغير، أو التبـديل والمسـؤول عنهـ Prefrontal cortex Left والتحضير والمسؤول عنه (prefrontal and) medial frontal areas .(dorsolateral prefrontal cortex) (Stuss.etal., 1995)

نظرية دونكان لتجاهل الهدف Duncan s goal-neglect theory

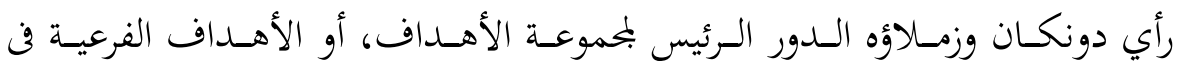

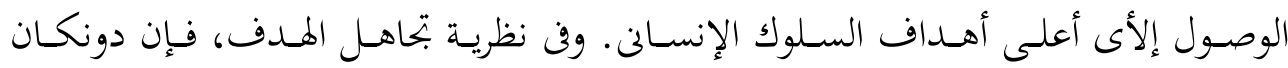

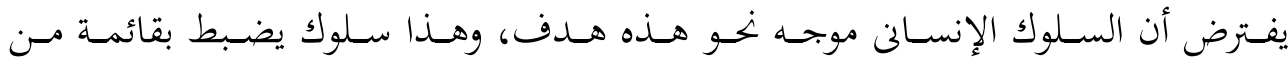

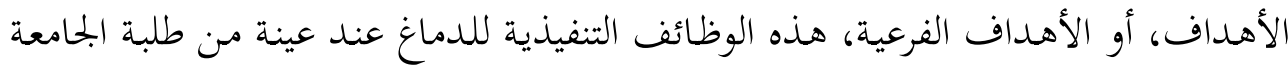
الأردنية وعلاقتها بالنوع الاجتماعى الاهد الفرعية هده

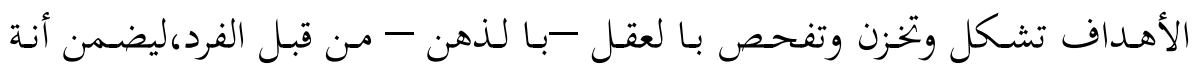

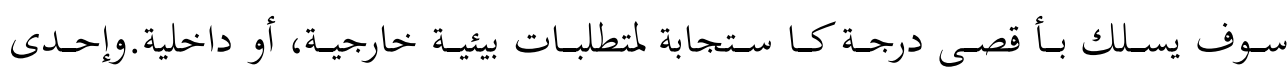

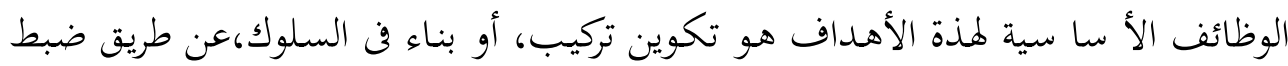

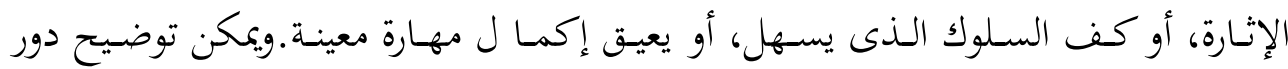

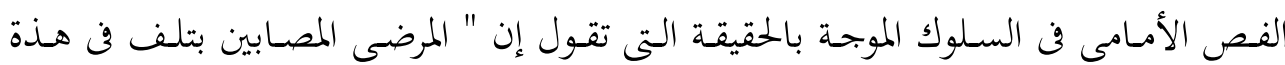

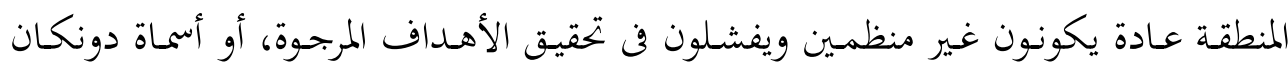

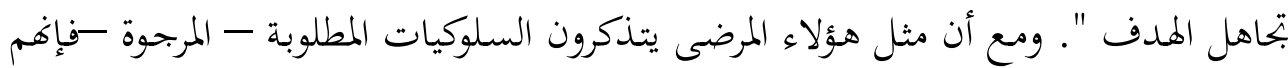

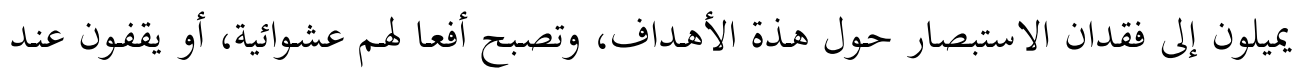
واحد، أو أكثر من الأهداف، الفرعية ( Duncan. 1986: Duncan, 8: Owen, .$(2000$

نموذج جولدمان -راكيك للذاكرة العاملة

Goldman - Rakic's working memory model 
إن هذا النموذج مبنى أسـا سـا على الدراسات التى أجريـت على الحيوانـا ت،وهى

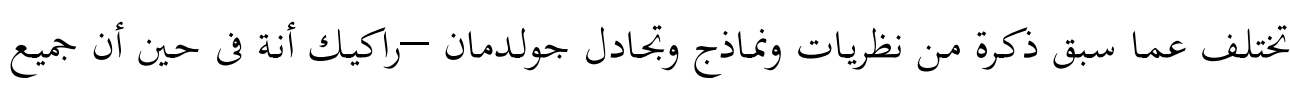

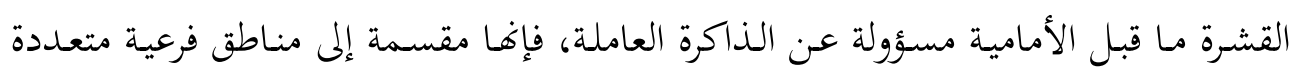

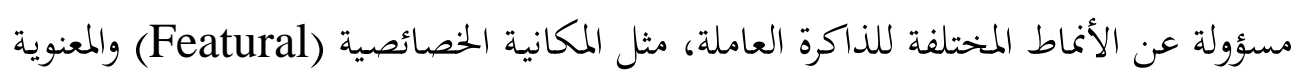
والمعرفة الرياضية

وتستكمل القشرة مـا قبل الأمامية هذة الوظائف عن طريق ممرين متبادلين (الكف الكف الكبة

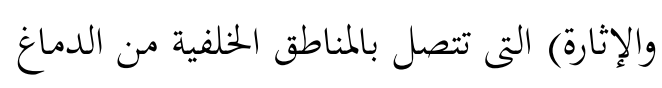

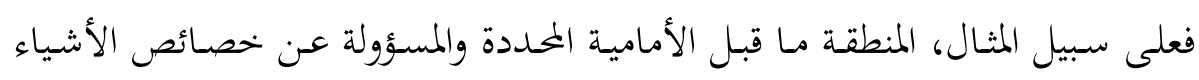

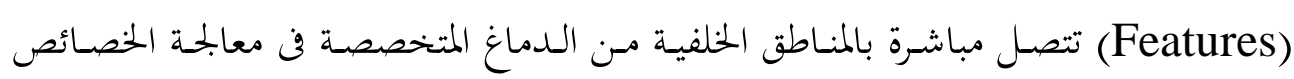

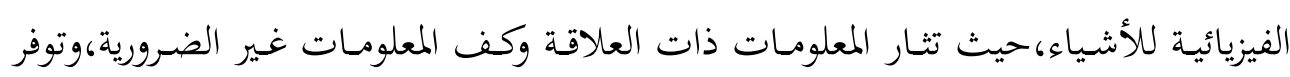

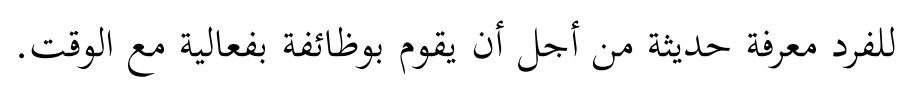

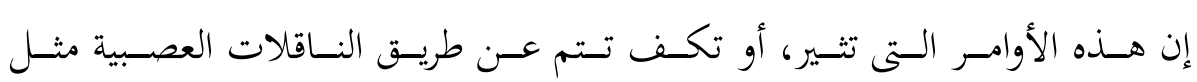

(Dopamine) وخصوصا الدوبامين (Catecholamines)

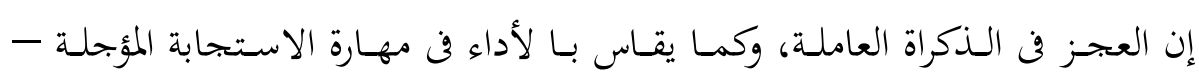
(delayed

يلاحظ عند القردة التى عندها تلف فن الدماغ، مما أدى إلى

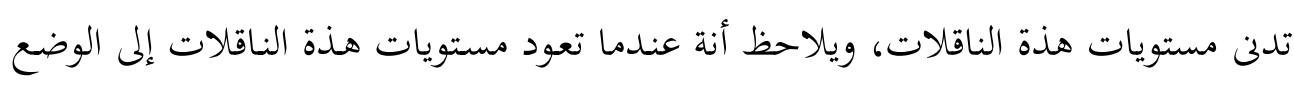

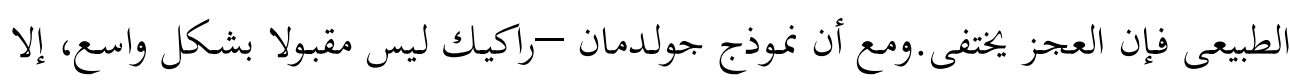

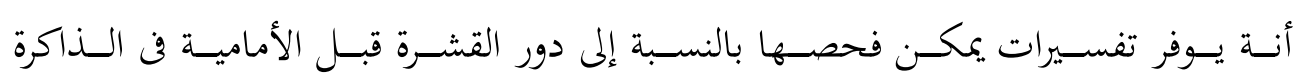

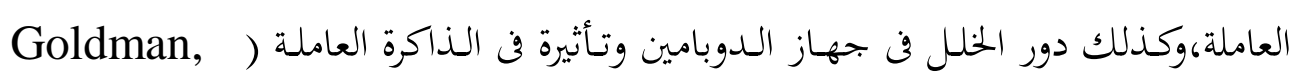
.(Rakic, 1992

فرضية دو ماسيو للإشارة الجسدية Damasio's Somatic Marker

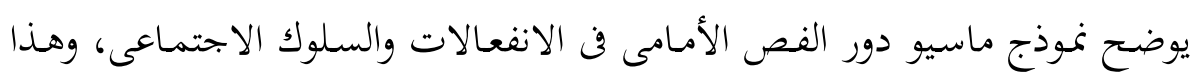

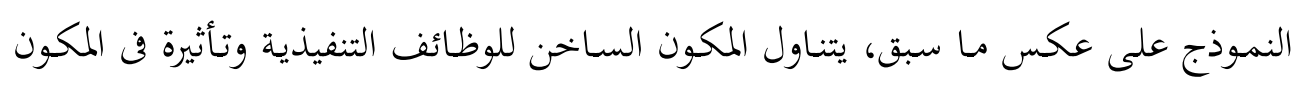


البارد، وكذلك فن عملية اتخاذ القرارات اليومية والعلاقات البينشخصية. ولقد وضع دوماسيو

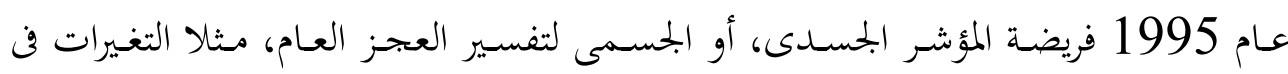
الشخصية والمشكلات الانفعالية والبين شخصية، التى تحـدث بعد تلف في الجزء البطنى

الأوسط من القشرة الأمامية (Ventromedial frontal Cortex). وذلك كما حدث عند المريض Phineas Gage ويرى دوماسيو أن الأفعال تتوسط

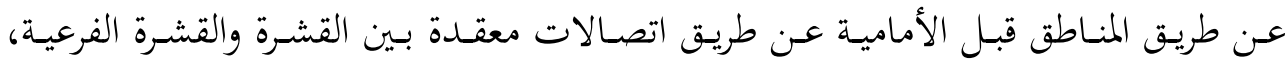

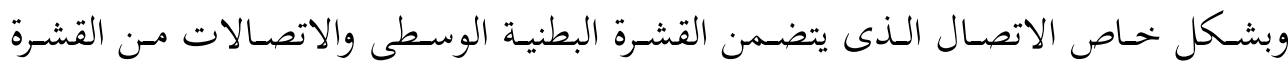

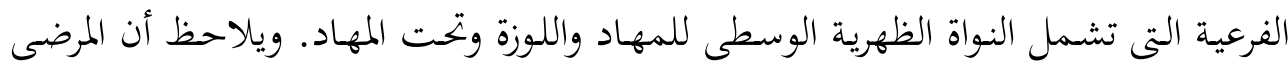
الذين عندهم تلف فن القشـرة الظهرية الوسطى للفص الأمـامى لا يستطيعون أن يربطوا

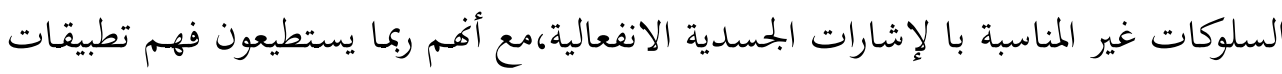

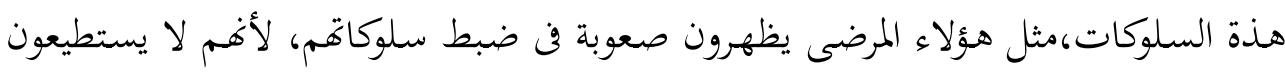

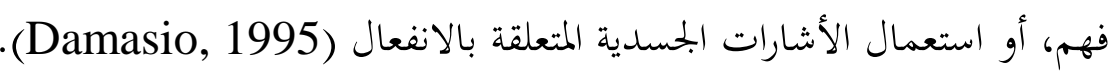

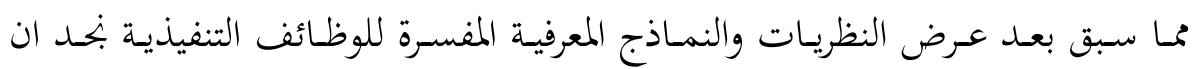

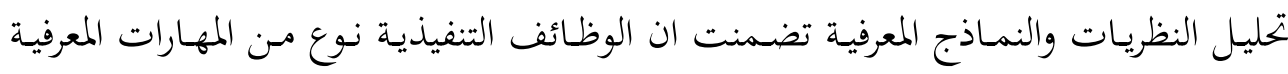

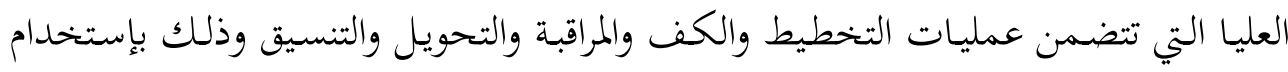

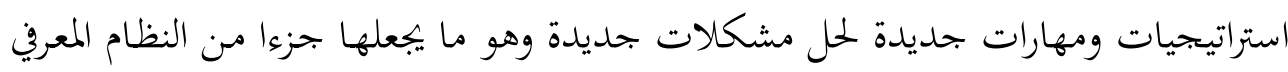

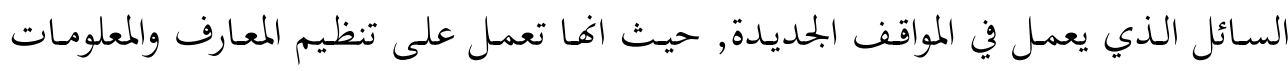

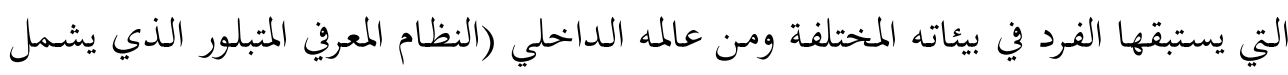

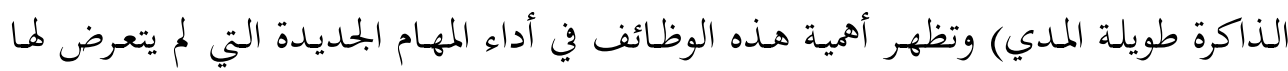

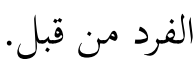

وتبنـت الباحثـة في البحـث الحسالي الاتجـاه الـذي يعتبر أن الوظـائف التنفيذيـة هي

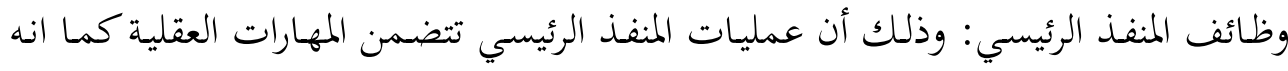
المسؤل معرفيا عن حل المشكلات الجديدة.

الوظائف التنفيذية والتواصل اللفظي لدى ضعاف السمع: 
استهدفت دراسة Gary Morgan (2016) الكشف عن التأثيرات البيئية على

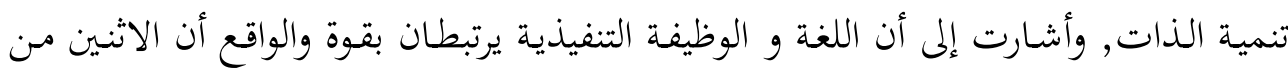

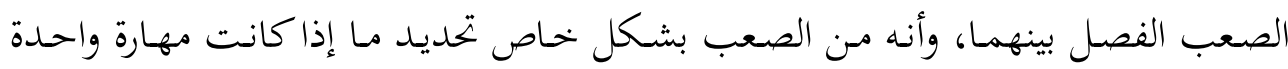

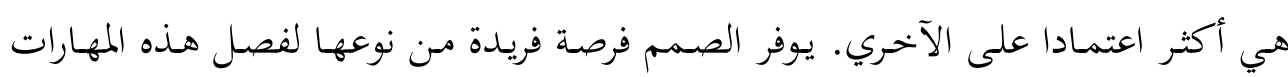

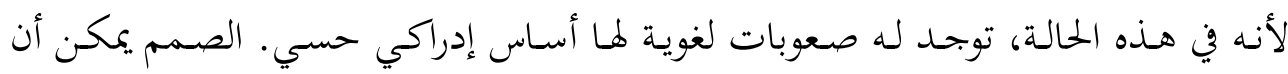

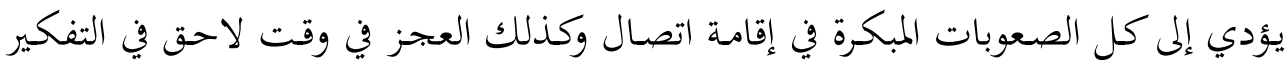

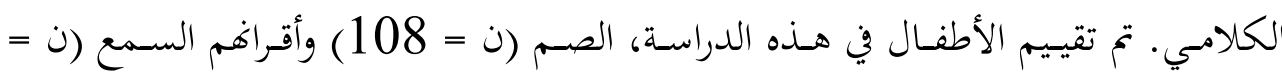

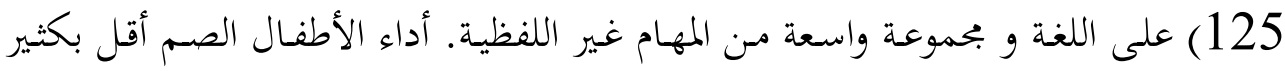

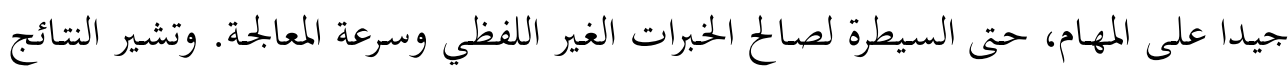

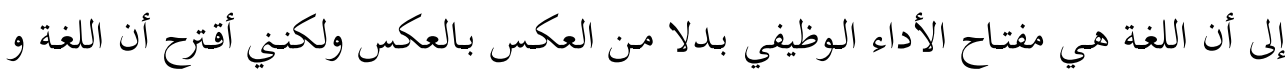
الوظائف قد تتغير العلاقة بينهما خلال عملية التنمية. فيما استهدفت دراسة AuBuchon, Angela Pisoni, (2015) اللفظية وسرعة المعالجة والأداء التنغيذي طويلة الأجل لزارعي القوقعة وكان الغرض من هذه الدراسة

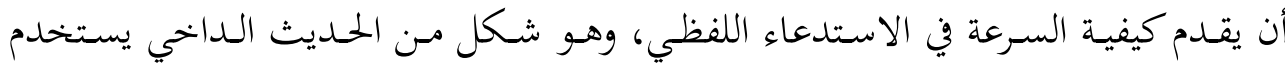

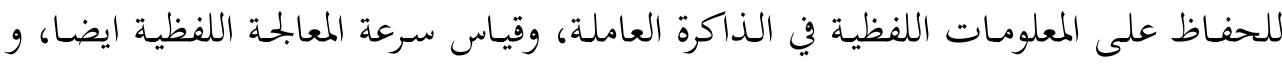

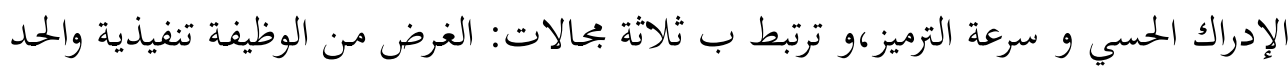

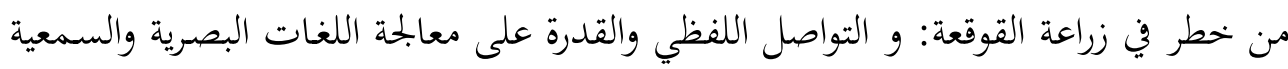
من خحلال خطاب الاتصالات.

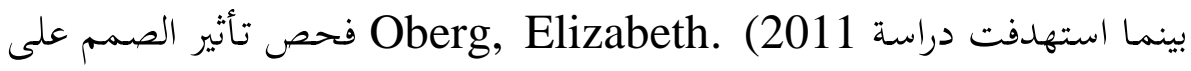
سلوكيات الأداء التنفيذي للطفل وقدرات الأداء على البحالات العصبية والمعرفية والإنجازات

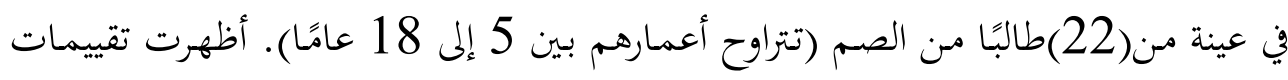
الوالدين والمعلمين في قائمة تصنيف السلوك للوظيفة التنفيذية (BRIEF) ارتباطات إيجابية

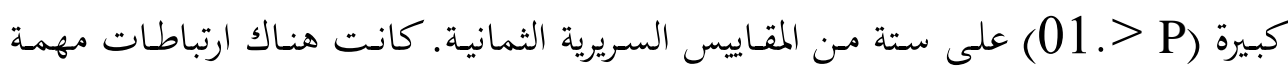

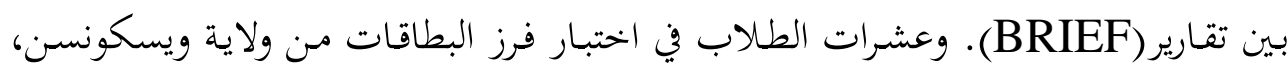
واختبار مسارات الألوان (للأطفال) واختبار Woodcock-Johnson). Writing 
Fluency

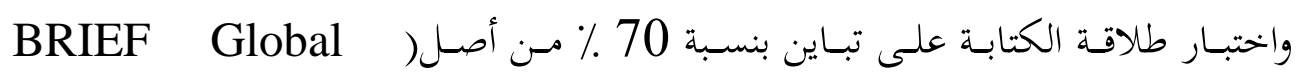
Executive Composite

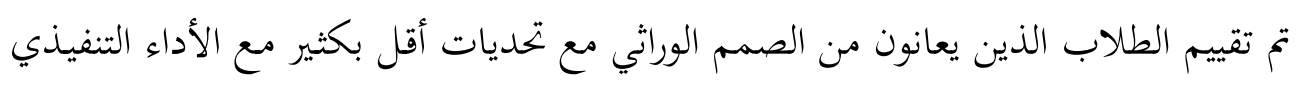

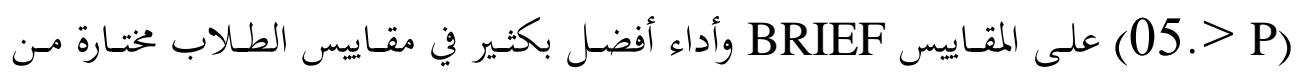
الطلاب الذين يعانون من أسباب أخرى للصمم.

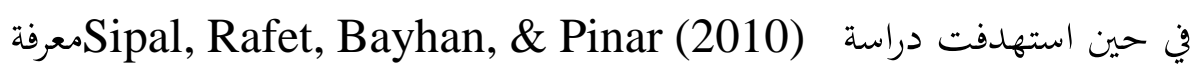

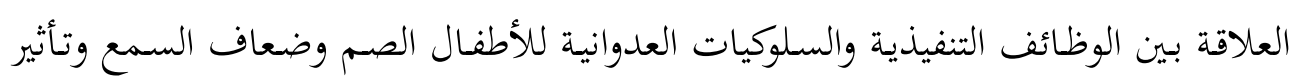

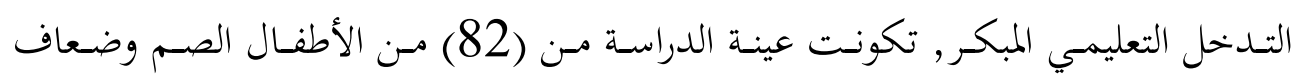

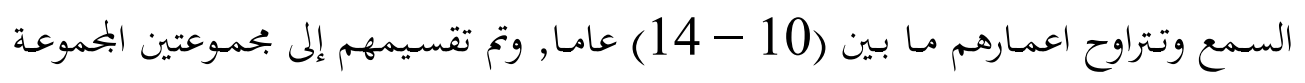

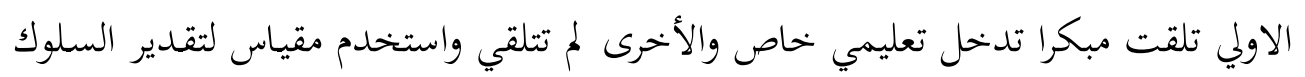

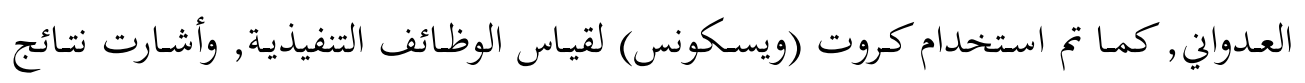

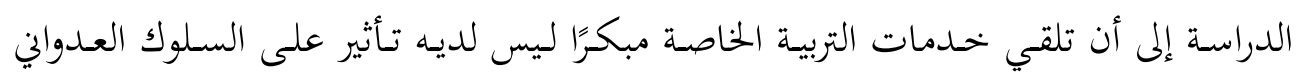

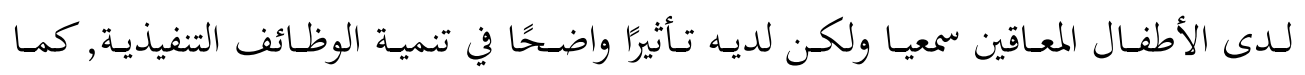

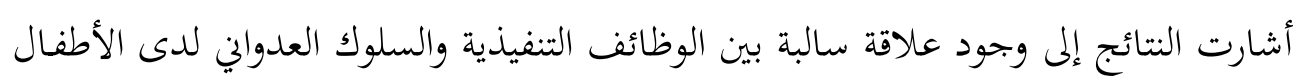
المعاقين سمعيا.

مراسة معرفة العمليات العصبية مثل التنفيذية

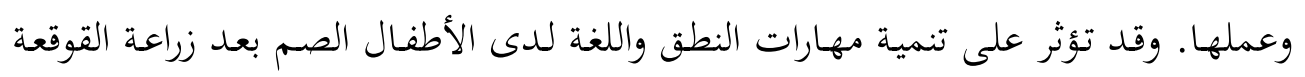

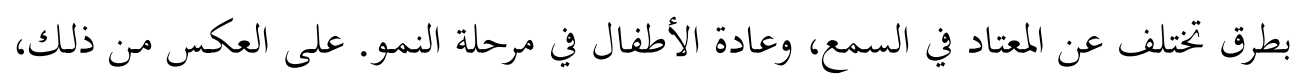

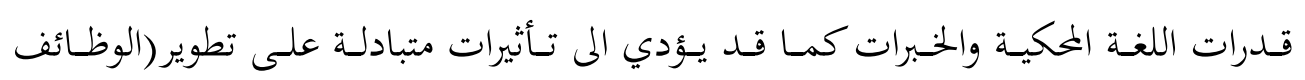
التنفيذية و العمليات المعريف ومهارات التحدث). دراسة Hyejinm (2014) هذه الدراسة تقييم للمهارات اللغوية وقدرات السرد

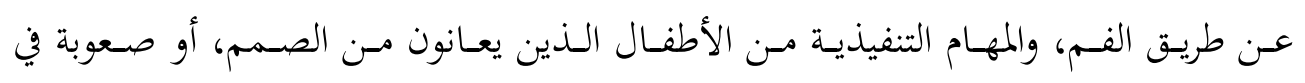

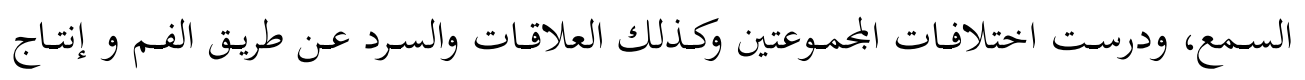

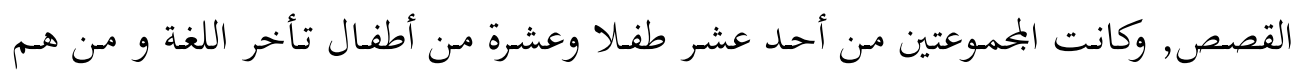


ضعاف السمع، وكانت اعمارهم من (9 سنوات ل 11 سنة) سنة، وشارك في الدراسة.

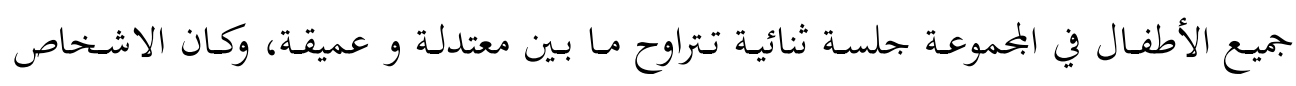

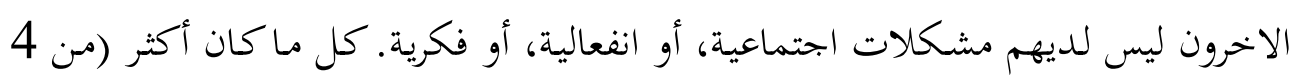

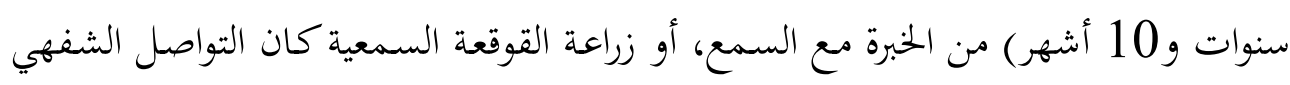

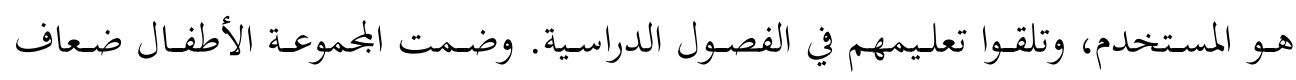

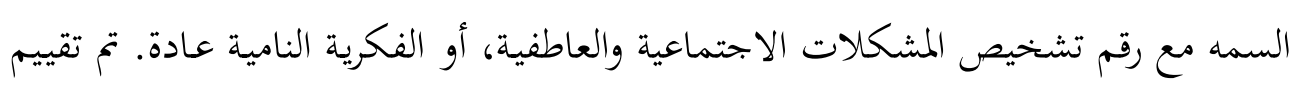

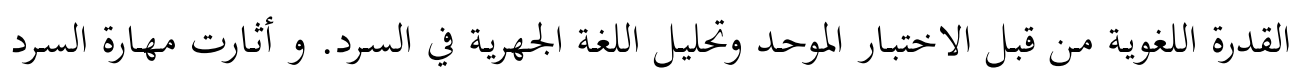

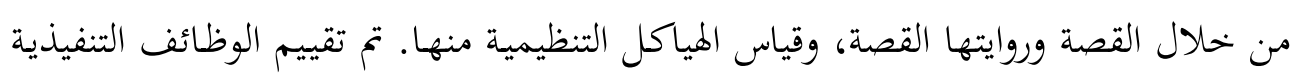
بطريقتين.

فيما تناقش دراسة Hintermair المشكلات السلوكية لضعاف السمع و الصم

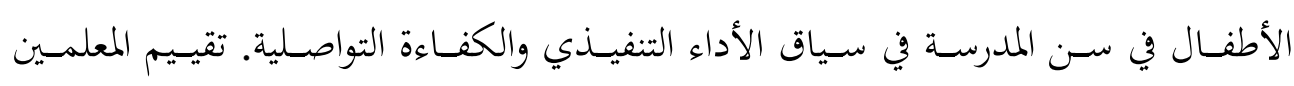

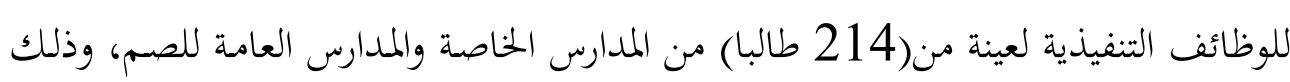

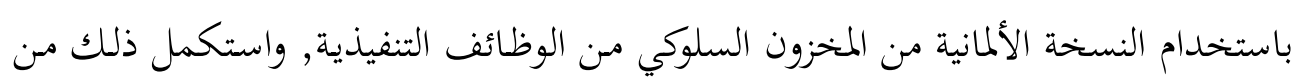

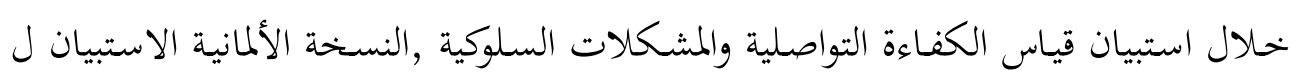

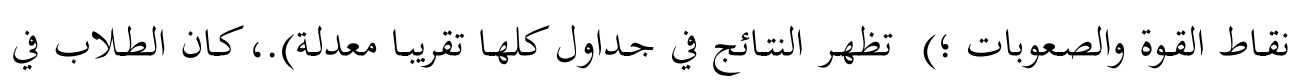

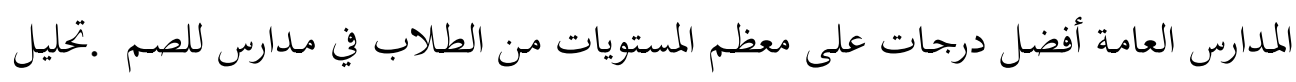

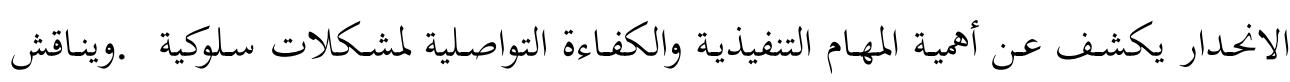

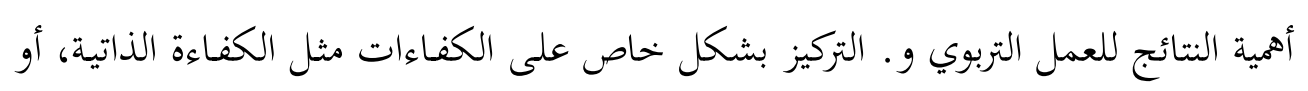

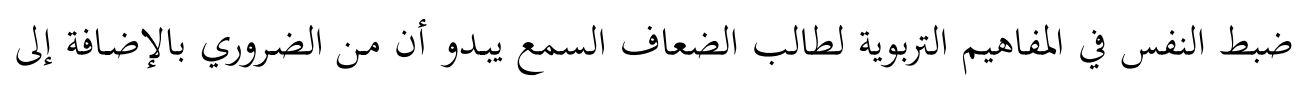
توسيع اختصاصات اللغة.

تناولت هذه الدراسة مسألة دور الذي تلعبه الوظائف التنفيذية في تطوير الطلاب

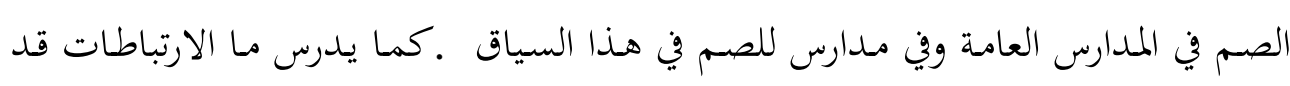

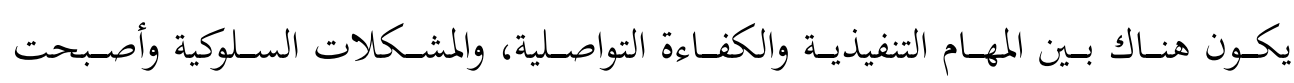

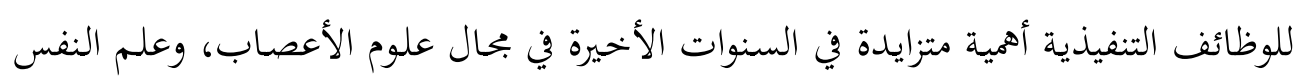


المعرفي، والتعليم، وذلك أمر مهم لكلا النظرية والممارسة التعليمية أن تدرس بعناية دور المهام التنفيذية في تطوير الطلاب.

دراسة (2011) Karpicke تصور الخطاب ينطوي على عدد من العمليات المعرفية

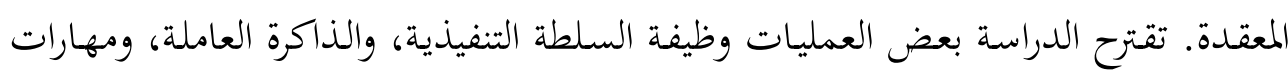

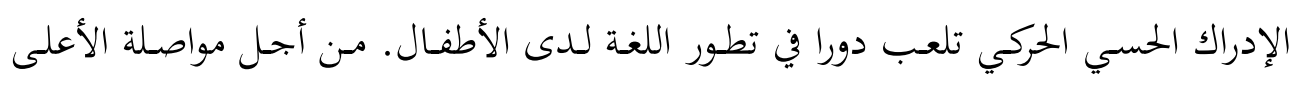

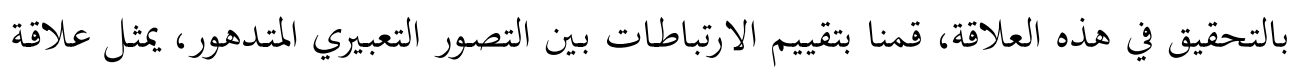

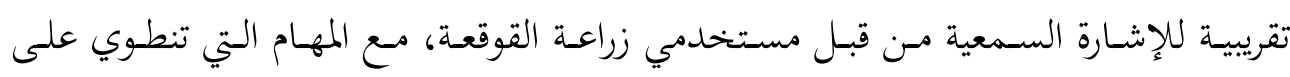

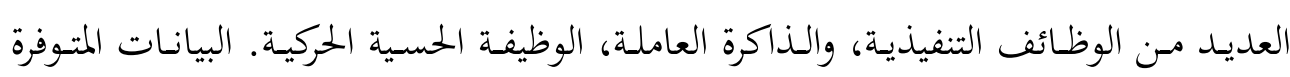

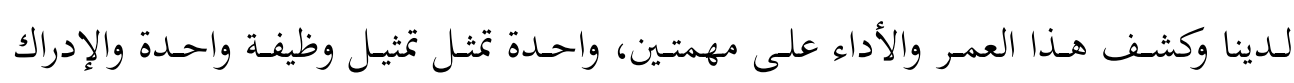

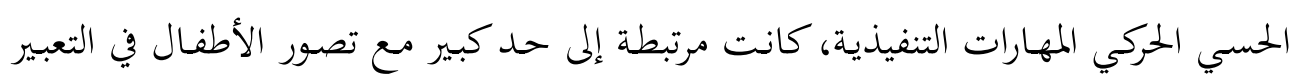

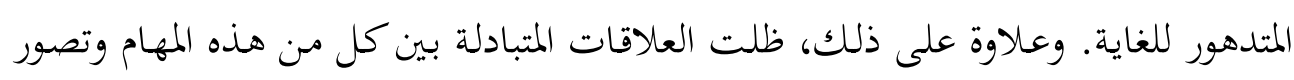

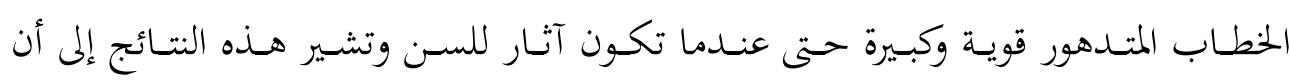

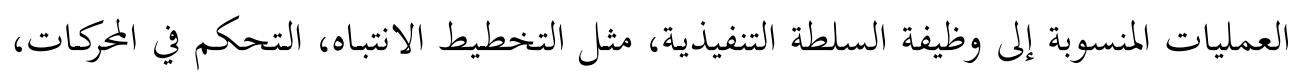

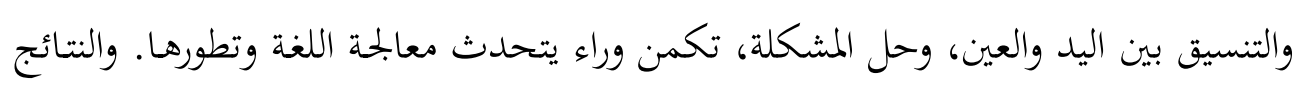

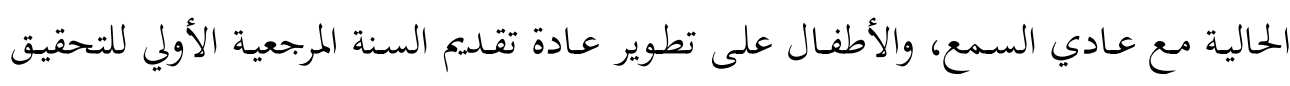

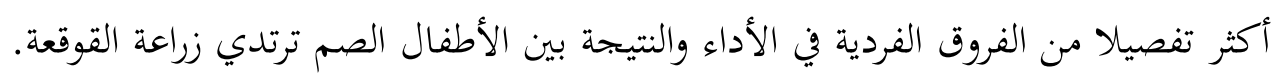

$$
\text { تعقيب عام على الدراسات السابقة:- }
$$

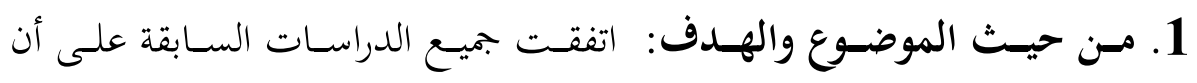

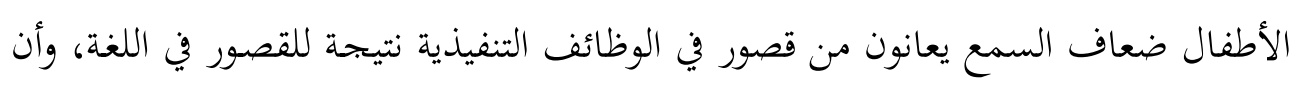

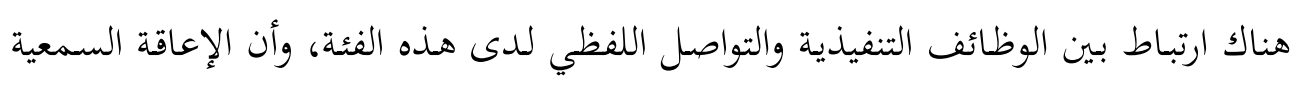
لدى الطفل تُحد إلى درجة كبيرة من الكتساب اللغة.

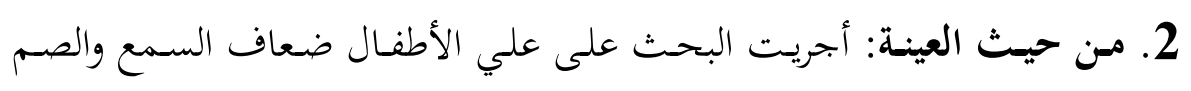

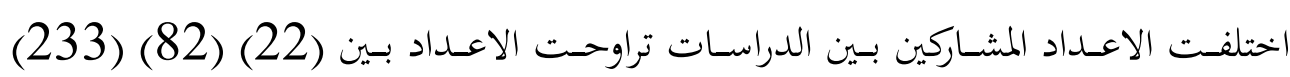


3. مـن حيـث الأدوات: اعتمــت الدراسـات على اختبـار لمشـكلات الوظـائف

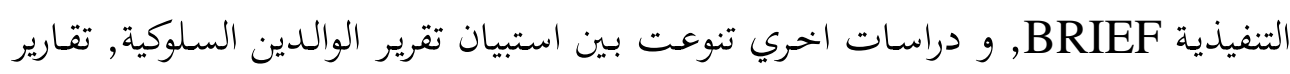

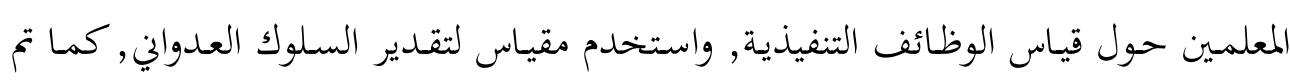
استخدام كروت (ويسكونس) لقياس الوظائف التنفيذية.

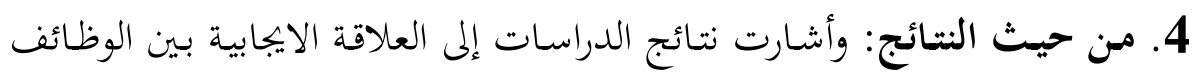

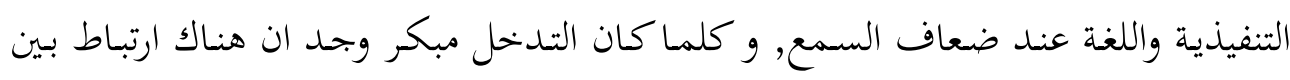
العمليات المعرفية التي تشكل السلوك لدى ضعاف السمع والمهارات العقلية والمعرفية.

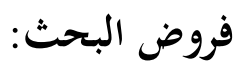

1 ـــ هل توجد علاقات ارتباطية دالة إحصائيًا بين درجات مقياس الوظائف التنفيذية

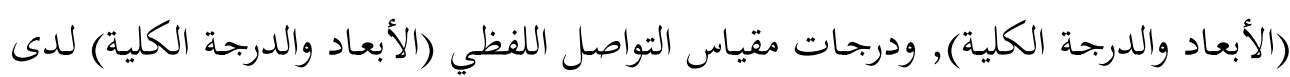

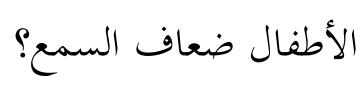

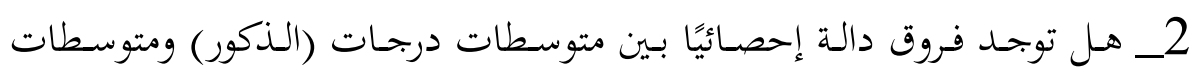
درجـات (الإنـاث) مـن الأطفـال ضـعاف السـمع في مقيـاس الوظـائف التنفيذيـة (الأبعـاد والدرجات الكلية)

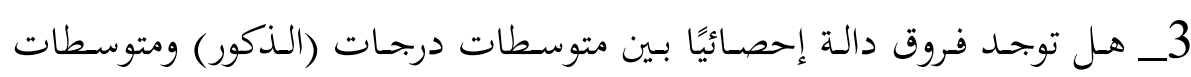
درجـات (الإنـاث) مـن الأطفــال ضـعاف السـمع في مقيـاس التواصـل اللفظـي (الأبعـاد والدرجات الكلية) (رجات

$$
\text { إجراءات البحث: }
$$

1- 1 منهج البحث: استخدمت الباحثة المنهج الوصفي.

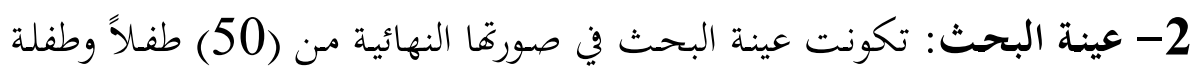

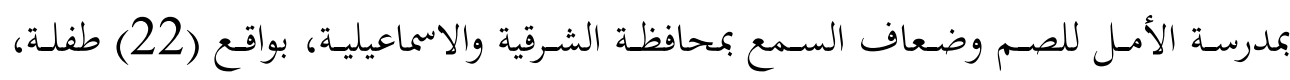

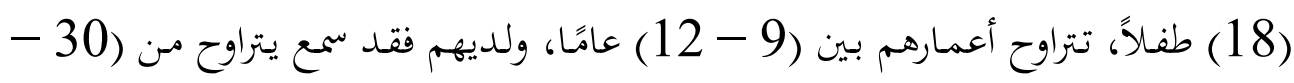

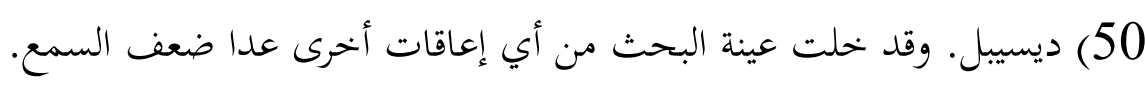




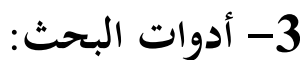

1 - مقياس التواصل اللفظي لضعاف السمع (اعداد الباحثة)

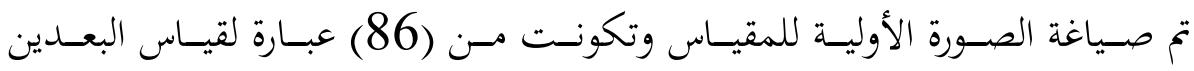

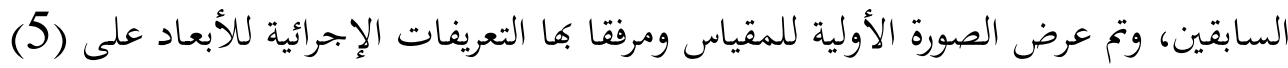

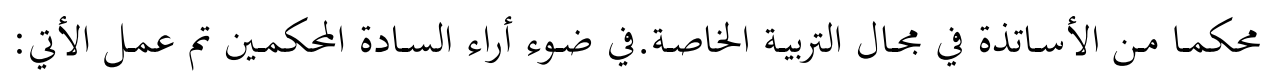

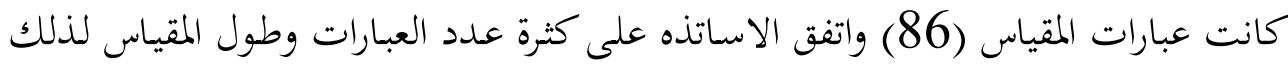

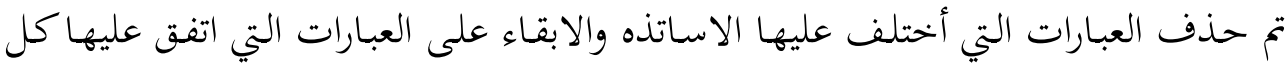

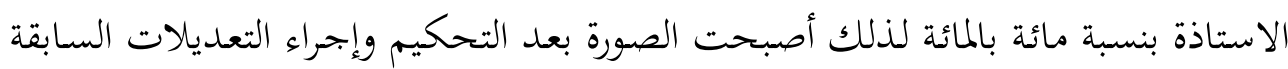

$$
\text { مكونة من (61). }
$$

2-2 - الوظائف التنفيذية لضعاف السمع (اعداد الباحثة)

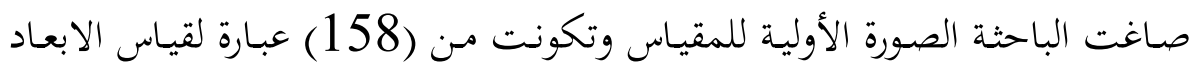

السابقة

تم عرض الصـورة الأولية للمقياس ومرفقـا بهـا التعريفـات الإجرائية للأبعاد على (5)

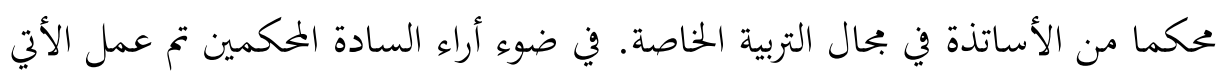

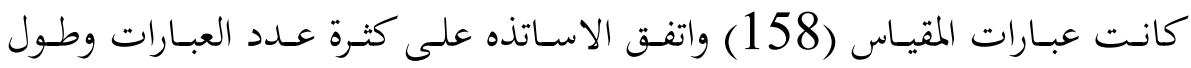

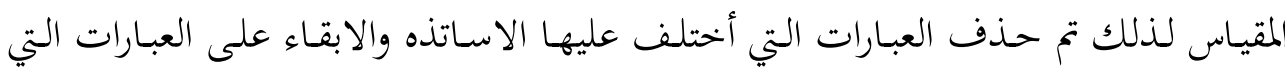

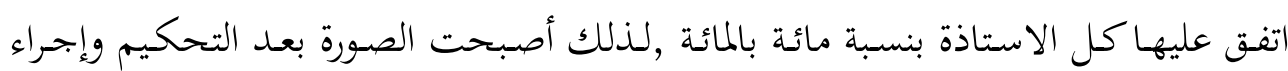

التعديلات السابقة مكونة من (73)عبارة.

خطوات البحث:

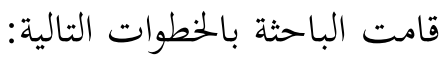

اطلعـت الباحثـة على ملفـات الأطفـال في مدرسـة بمحافظـة الشـرقية والاسماعيليـة

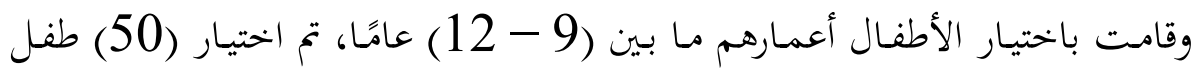

وطفلة من تنطبق عليهم الشروط، وبمساعدة مدرس الفصل قام الباحث بما يلي:

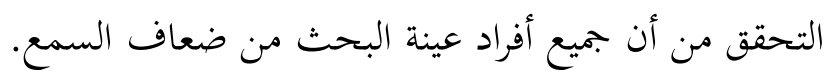


أُحادية الإعاقة، أي لا توجد إعاقات مصاحبة لضعف السمع لدى أفراد العينة.

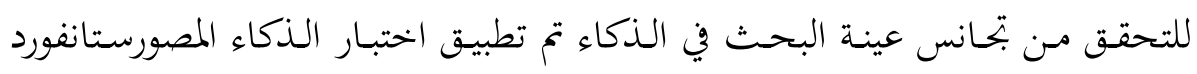

$$
\text { بينه (الصورة الخامسة) }
$$

تطبيق مقياس الوظائف التنفيذية (اعداد الباحثة)

$$
\text { تطبيق مقياس اضطراب التواصل اللفظي (اعاد الباحثة) }
$$

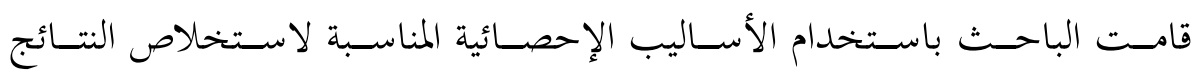

$$
\text { وتفسيرها. }
$$

\section{الأسلوب الإحصائي المُستخدم في البحث:}

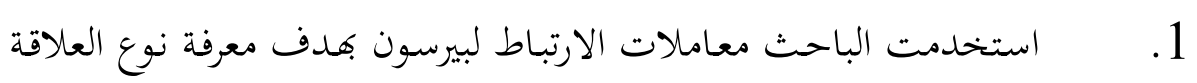
الارتباطية الوظائف التنفيذية واضطرابات التواصل اللفظي 2. استخدمت الباحثة اختبار (ت) لحساب دلالة الفروق بين المتوسطات.

\section{نتائج البحث

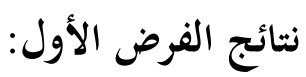

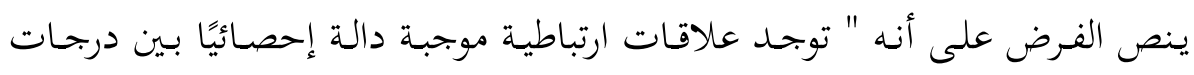

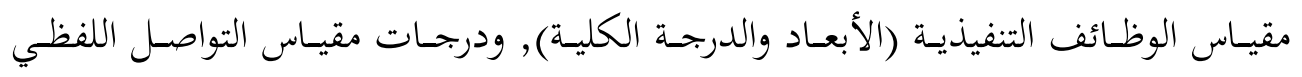

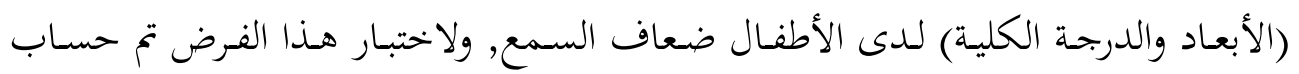

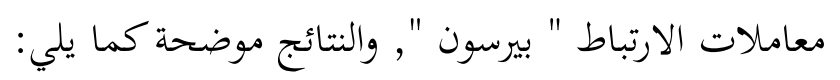

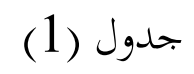

\begin{tabular}{|c|c|c|c|}
\hline \multicolumn{3}{|c|}{ معاملات الارتباط مع درجات مقياس التواصل اللفظي } & \multirow{2}{*}{ مقياس الوظائف التنفيذية } \\
\hline الدرجة الكلية & اللغة التعبيرية & اللغة الاستقبالية & \\
\hline 0,079 & 0,186 & 0,156 & التخطيط \\
\hline
\end{tabular}

معاملات الارتباط بين درجات مقياس الوظائف التنفيذية (الأبعاد والدرجة الكلية) ودرجات

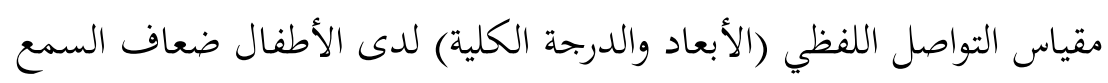




\begin{tabular}{|c|c|c|c|}
\hline 0,134 & 0,153 & 0,111 & الذاكرة العاملة \\
\hline *** 0,544 & *** 0,506 & *** 0,460 & المراقبة الذاتية \\
\hline$* * 0,419$ & *** 0,397 & *** 0,349 & المرونة العقلية \\
\hline 0,159 & 0,235 & 0,162 & التحكم العقلي \\
\hline 0,147 & 0,125 & 0,155 & الدرجة الكلية للمقياس \\
\hline
\end{tabular}

(1) معاملات الارتباط بين درجات التخطيط ودرجات كل من: اللغة الاستقبالية,

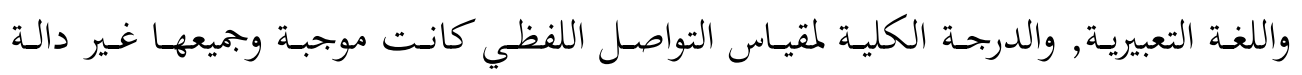
إحصائيًا.

(2) معـاملات الارتبـاط بـين درجـات الـذاكرة العاملـة ودرجـات كـل مـن: اللغـة

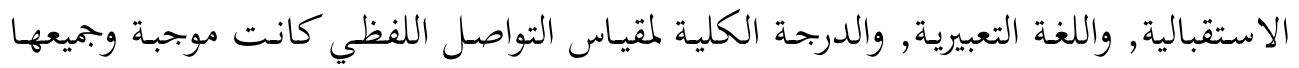
غير دالة إحصائيًا.

(3) معـاملات الارتبـاط بـين درجـات مراقبـة الـذات ودرجـات كـل مـن: اللغـة

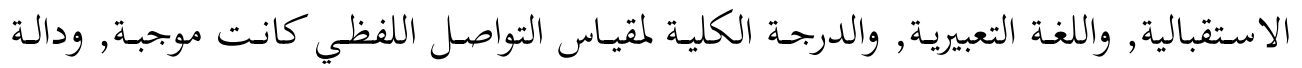

$$
\text { إحصائيًا (عند مستوي 0,01). }
$$

(4) معـاملات الارتبـاط بــن درجـات المرونـة العقليـة ودرجـات كـل مـن: اللغـة

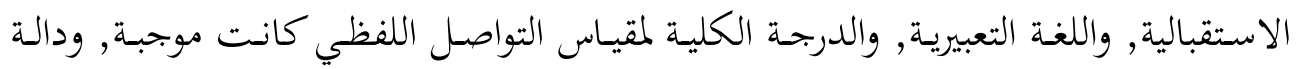

$$
\text { إحصائيًا (عند مستوي 0,01). }
$$

(5) معـاملات الارتبـاط بـين درجـات التحكم العقلي ودرجـات كـل مسن: اللغـة

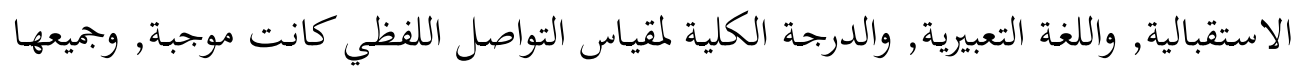
غير دالة إحصائيًا.

(6) معاملات الارتباط بين الدرجة الكلية لمقياس الوظائف التنفيذية ودرجات كل

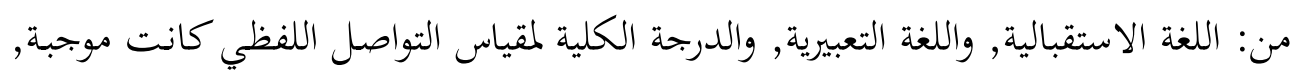
وجميعها غير دالة إحصائيًا. 
وتتفق هذه النتائج مع الدراسات التي وجدت هناك ارتباط قوي بين إنتاج الكلام

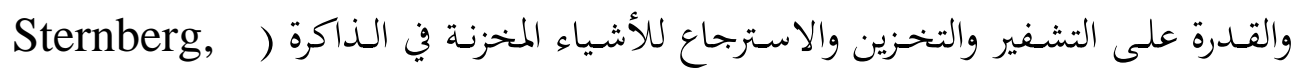

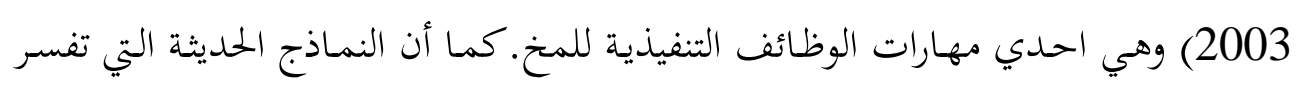

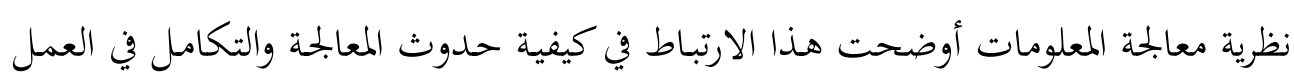

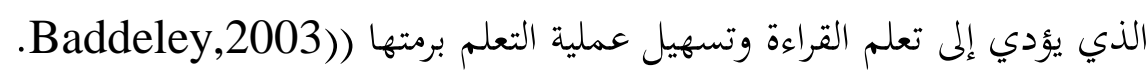

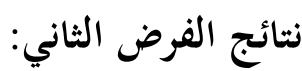

ينص الفرض على أنه: لا توجهد فروق دالـة إحصائيًا بين متوسطات درجـات (الذكور)

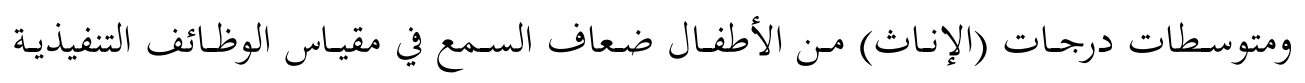

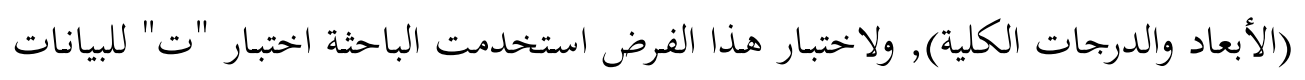

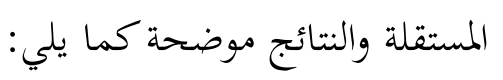
جدول (2)

الفروق بين متوسطات درجات الذكور ومتوسطات درجات الإناث في مقياس الوظائف التنفيذية

\begin{tabular}{|c|c|c|c|c|c|c|}
\hline الدلالة & قيمة (ت) & الانحراف المعياري & المتوسط & العدد & البمموعات & مقياس الوظائف \\
\hline \multirow{2}{*}{ غير دالة } & \multirow{2}{*}{1,149} & 4,20 & 28,44 & 18 & (الذكور) & \multirow[t]{2}{*}{ التخطيط } \\
\hline & & 3,95 & 29,81 & 32 & (الإناث) & \\
\hline \multirow{2}{*}{ غير دالة } & \multirow{2}{*}{0,271} & 4,37 & 32,94 & 18 & (الذكور) & \multirow[t]{2}{*}{ الذاكرة العاملة } \\
\hline & & 3,50 & 32,25 & 32 & (الإناث) & \\
\hline \multirow{2}{*}{ غير دالة } & \multirow{2}{*}{0,049} & 4,36 & 25,59 & 18 & (الذكور) & \multirow{2}{*}{ المراقبة الذاتية } \\
\hline & & 3,54 & 25,53 & 32 & (الإناث) & \\
\hline \multirow{2}{*}{ غير دالة } & 0,159 & 4,29 & 28,61 & 18 & (الذكور) & \multirow{2}{*}{ المرونة العقلية } \\
\hline & & 3,22 & 28,78 & 32 & (الإناث) & \\
\hline \multirow{2}{*}{ غير دالة } & 0,260 & 4,17 & 30,33 & 18 & (الذكور) & \multirow{2}{*}{ التحكم العقلي } \\
\hline & & 3,60 & 30,63 & 32 & (الإناث) & \\
\hline غير دالة & 0,535 & 14,84 & 145,94 & 18 & (الذكور) & الدرجة الكلية \\
\hline
\end{tabular}




\begin{tabular}{|l|l|l|l|l|l|l|}
\hline & & 11,64 & 148,00 & 32 & (الإناث) & (لمقياس \\
\hline
\end{tabular}
يتضح من الجدول السابق: أن جميع الفروق بين متوسطات درجات الذكور ومتوسطات درجات الإناث في جميع

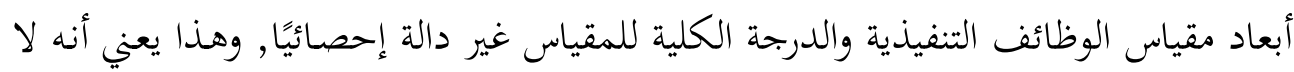

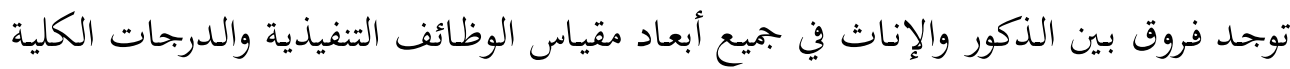

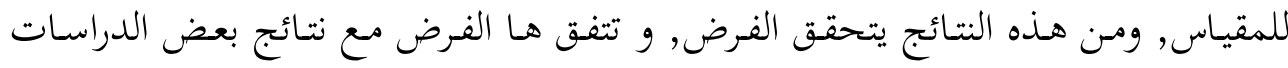

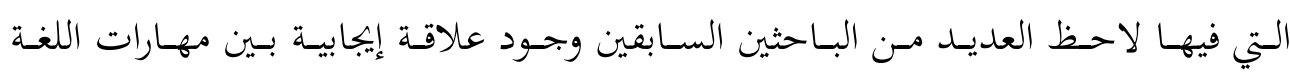

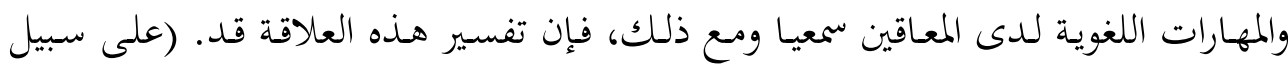

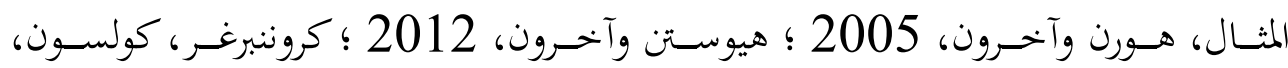

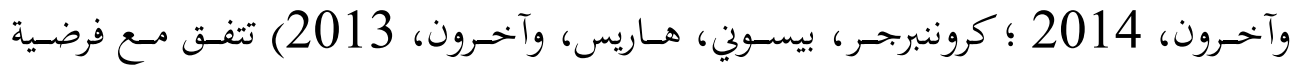

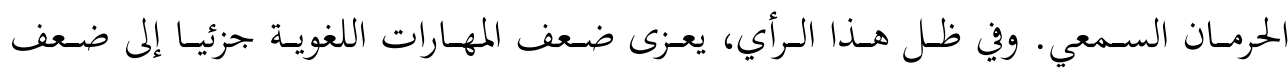
المهارات المعرفية عموما، والتي تعزى بدورها، جزئيا على الأقل، إلى نقص الخبرة السمعية.

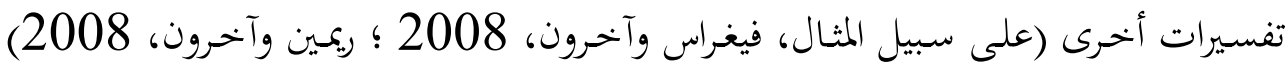

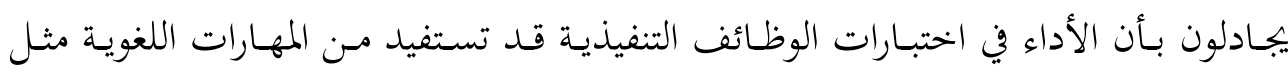

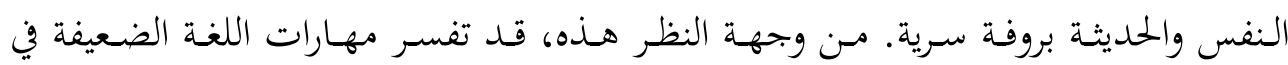

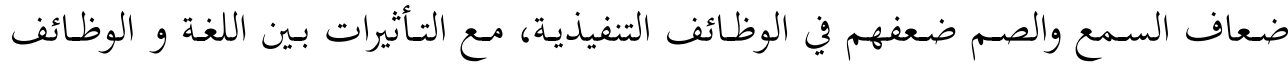

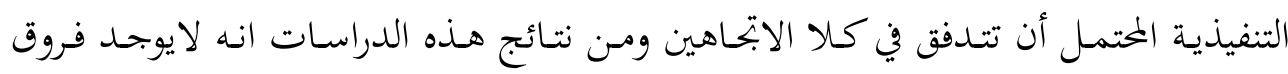
ذات دلالة احصائية بين الاناث والذكور من حيث الوظائف التنفيذية.

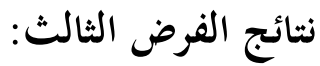

ينص الفرض على أنه: لا توجد فروق دالة إحصائيًا بين متوسطات درجات (الذكور)

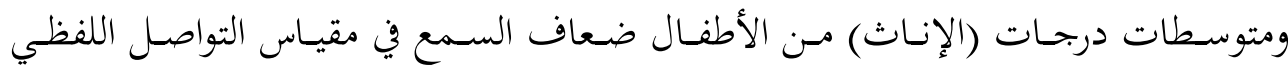

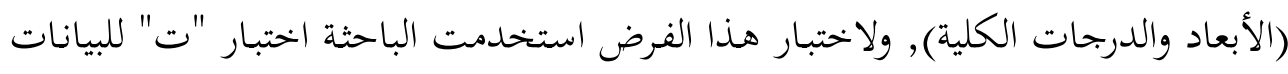

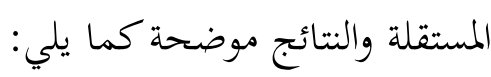

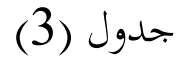


الفروق بين متوسطات درجات الذكور ومتوسطات درجات الإناث

\begin{tabular}{|c|c|c|c|c|c|c|}
\hline الدل الدالة & قيمة (ت) & الانحراف المعياري & المتوسط & العدد & البمموعات & مقيـــــــاس التواصـــــلـ \\
\hline \multirow{2}{*}{ غــــير } & \multirow{2}{*}{0,843} & 11,10 & 78,22 & 18 & (الذكور) & \multirow[t]{2}{*}{ اللغة الاستقبالية } \\
\hline & & 13,49 & 81,38 & 32 & (الإناث) & \\
\hline \multirow{2}{*}{ غــــير } & \multirow{2}{*}{0,588} & 11,30 & 71,56 & 18 & (الذكور) & \multirow[t]{2}{*}{ اللغة التعبيرية } \\
\hline & & 10,32 & 73,41 & 32 & (الإناث) & \\
\hline \multirow{2}{*}{ عــــير } & \multirow[t]{2}{*}{0,823} & 16,90 & 149,78 & 18 & (الذكور) & \multirow{2}{*}{ اللفظة الكلية للتواصل } \\
\hline & & 22,43 & 154,78 & 32 & (الإناث) & \\
\hline
\end{tabular}

يتضح من الجدول السابق:

أن جميع الفروق بين متوسطات درجات الذكور ومتوسطات درجات الإناث في جميع

أبعاد مقياس التواصل اللفظي والدرجة الكلية للمقياس غير دالة إحصائيًا, وهذا يعني أنه لا توجد فروق بين الذكور والإناث في كل من اللغة الاستقبالية واللغة التعبيرية والدرجات الكلية للتواصل اللفظي, ومسن هذه النتائج يتحقق الفرض وهذا يتفق ونتائج بعض الدراسات التي (Moeller, أكدت انه لا يوجد فروق بين الاناث والذكور في اللغة الاستقبالية والتعبيرية 2000) (Calderon, 2000) (stevenson Jim ,et:2010) 


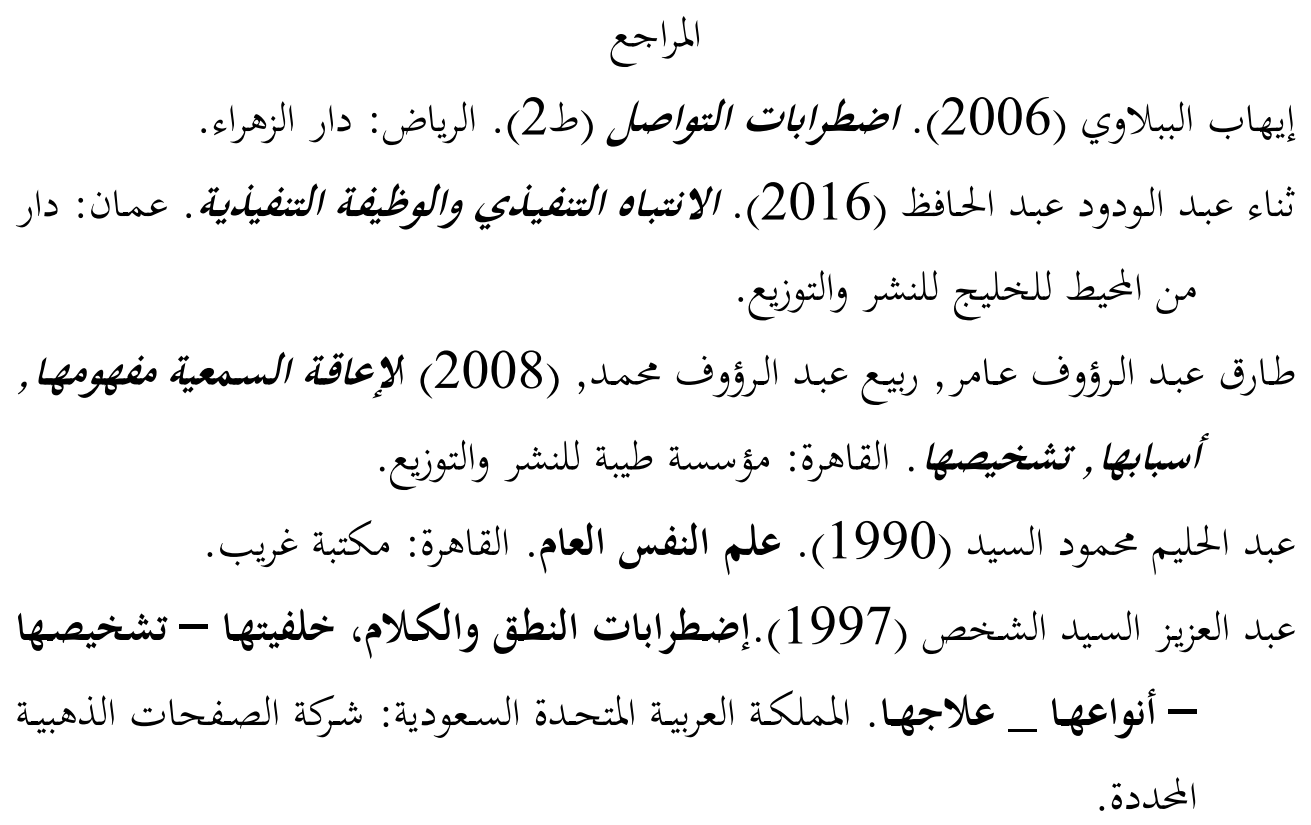

Adler, R. \& Rodman, G. (2006). Understanding human communication. (9 $9^{\text {th }}$ ed.). New York: Oxford University Press 
AuBuchon, A., Pisoni, D., Kronenberger, W. (2015). Processing speed and executive functioning in longterm cochlear implant users, Journal of Speech, Language, and Hearing Research, 2015.

Morin, A., (2014). Executive function http:// www. webmd.com/add- adhd/guide/executive- function

Baars, B. (2003). The Global Brain Web. Science \& Consciousness Review, October, No 2.1-9.

Baddeley, A. (1996). The Fractionation of Working Memory., Proc.Nat. ACad..93, 13468-134320.

Baddeley, A. D. (2003). Working memory and language: an overview. Journal of Communication Disorders, 36, (3), 189-208.

Burkey, J. (2006). Baby boomers and hearing loss: A guide to prevention and care. New Brunswick: Rutgers University Press

Coldern, R. (2000). Parental involvement and children, Education programs as a predictor of child's language, early. reading and social emotional development Journal of Deaf Studies and Deaf Education, 5 , 140 .

Damasio,A. (1994). Descartes'error: Emotion, reason, and the human brain. New York: Putnam.

Figueras, Berta;(2008). Executive function and language in deaf children ,edwards, lindsey; langdon, dawn Journal of Deaf Studies and Deaf Education, 2008

Gary Morgan:(2016). Executive functions and language development in deaf and hearing children.(City University, London) Tuesday 1st March 2016, 11 12.30 Room 2.219, University Place, University of Manchester

Gutierrez-Ang, J. (2009). Oral communication: Accounted-based and learning centered text-manual 
in effective speech communication. 2nd ed. Philippines: Katha Publishing Co., INC.

Kimberly peters.(2013). Executive Function in Children who are Deaf/Hard

of Hearing www.seattlechildrens.org/pdf/petersexecutive-functions Kimberly peters 2013

Manfred H.,(2013). Executive functions and behavioral problems in deaf and hard-of-hearing students at general and special school correspondence should be addressed to manfred hintermair, University of Education Heidelberg, Keplerstraße 87, D-69120 Heidelberg, Germany (e-mail: hintermair@ phheidelberg.de).

Moller, M., (1993). Early intervention language development in children who are deaf of hard of hearing Journal of Pediatrics, 106, (3).

Remine, M., (2008). Language Ability and Verbal and Nonverbal Executive Functioning in Deaf Students Communicating in Spoken English Care, Esther; Brown, P. Margaret - Journal of Deaf Studies and Deaf Education, 2008.

Sipal, R., (2010). Assessing the Link between Executive Functions and Aggressive Behaviors of Children Who Are Deaf: Impact of Early Special Education ,Bayhan, Pinar - Electronic Journal of Research in Educational Psychology, 2010.

Stach, B. (2010). Clinical audiology: An introduction. $2^{\text {nd }}$ ed. Canada: Delmar Cengage Learning.

Stevenson, J., Mccann, D., Watkin, P., Worsfold, S. \& Kenndy, C. (2010). The relationship between language development and behavior problems in children with hearing loss, Journal of Child Psychology and Psychiatry, 51 (1), 77. 
Taylor, B. \& McDonough, K. (1996). Selecting Teaching Programs. In C. Mauriee, G. Green and C.Stephen, Behavioral intervention for young children with autism: A manual for parents and professionals. Austin: PRO-ED, Incorporated.

Thomas Brown. (2005). The Brown Model of $A D D / A D H D$ http://www.drthomasebrown.com/addadhd-model. 